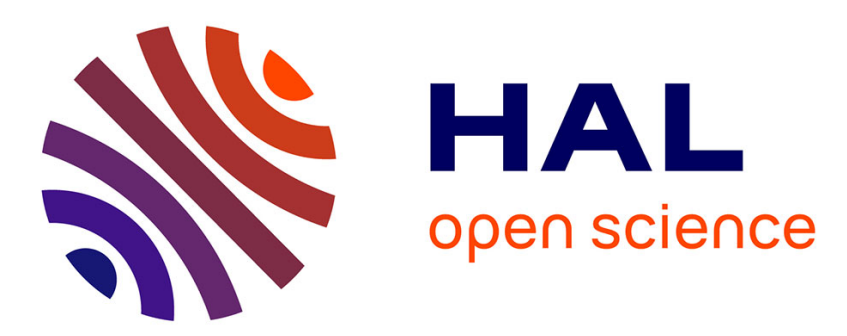

\title{
Experimental and Numerical Modeling of Segregation in Metallic Alloys
}

Salem Mosbah, Michel Bellet, Charles-André Gandin

\section{To cite this version:}

Salem Mosbah, Michel Bellet, Charles-André Gandin. Experimental and Numerical Modeling of Segregation in Metallic Alloys. Metallurgical and Materials Transactions A, 2010, 41 (3), pp.651-669. 10.1007/s11661-009-0141-6 . hal-00509607

\section{HAL Id: hal-00509607}

https://hal-mines-paristech.archives-ouvertes.fr/hal-00509607

Submitted on 3 Jan 2017

HAL is a multi-disciplinary open access archive for the deposit and dissemination of scientific research documents, whether they are published or not. The documents may come from teaching and research institutions in France or abroad, or from public or private research centers.
L'archive ouverte pluridisciplinaire HAL, est destinée au dépôt et à la diffusion de documents scientifiques de niveau recherche, publiés ou non, émanant des établissements d'enseignement et de recherche français ou étrangers, des laboratoires publics ou privés. 


\title{
Experimental and numerical modeling of segregation in metallic alloys
}

\author{
S. Mosbah, M. Bellet, Ch.-A. Gandin \\ MINES ParisTech, Ecole des Mines de Paris, Centre de Mise en Forme des Matériaux, \\ CEMEF UMR CNRS-ENSMP 7635, 06904 Sophia Antipolis, France
}

\begin{abstract}
Electromagnetic levitation has been used as an experimental technique to investigate the effect of nucleation and cooling rate on segregation and structure formation in metallic alloys. The technique has been applied to spherical aluminum-copper alloys. For all samples, the primary phase nucleation has been triggered by contact of the levitated droplet with an alumina plate at a given undercooling. Based on the recorded temperature curves, the heat extraction rate and the nucleation undercooling for the primary dendritic and the secondary eutectic structures have been determined. Metallurgical characterizations have consisted of composition measurements using a scanning electron microscope (SEM) equipped with energy dispersive X-ray spectrometry and analysis of SEM images. The distribution maps drawn for the composition, the volume fraction of the eutectic structure and the dendrite arm spacing reveal strong correlations. Analysis of the measurements with the help of a Cellular Automaton (CA) - Finite Element (FE) model is also proposed. The model involves a new coupling scheme between the CA and the FE methods together and a microsegregation model accounting for diffusion in the solid and liquid phases. Extensive validation of the model has been carried out demonstrating its capability to deal with mass exchange inside and outside the envelope of a growing primary dendritic structure. The model has been applied to predict the temperature curve, the segregation and the eutectic volume fraction obtained upon single grain nucleation and growth from the south pole of a spherical domain with and without triggering of the nucleation of the primary solid phase, thus simulating the solidification of a levitated droplet. Predictions permit a direct interpretation of the measurements.
\end{abstract}

\section{Keywords}

Solidification, Segregation, Modeling, Dendritic structure, Eutectic structure. 


\section{Introduction}

In the last two decades, numerical modeling of the solidification of metallic alloys has received great interest [1]. One of the main objectives is to achieve maximum control of the structure and segregation formed upon the solidification processes. Confrontation of such models with measurements is yet rarely completed due to the difficulty to defined model experiments in metallic alloys. Containerless techniques offer an advanced control since various degrees of nucleation undercooling can be achieved. In addition, the cooling rate, the system geometry and shape (generally spherical), the limited temperature gradient, and the low variation of the heat extraction rate throughout the entire surface of the system within the solidification interval define a suitable experimental model for equiaxed solidification. In the recent past, the atomization process was first proposed by Heringer el al. as an experimental model for the study of segregation induced by equiaxed growth [2]. Prasad et al. extracted a data set from several atomization runs of aluminum ( $\mathrm{Al})$ - copper $(\mathrm{Cu})$ alloys consisting of X-ray tomography, neutron diffraction and stereology [3, 4]. However, measurements of the nucleation undercooling of the primary dendritic and secondary eutectic structures were not directly available and had to be estimated from measurements using electromagnetic levitation of droplets [4]. ElectroMagnetic Levitation (EML) is also a containerless technique that can be seen as a model experiment for the atomization process [4]. Thanks to its combination with in situ temperature measurements, it can be used to collect information such as the cooling rate prior to and during solidification and the nucleation undercooling of the structures. In the work by Gandin et al., an analytical segregation model for the prediction of the temperature evolution upon primary dendritic and secondary eutectic growth was developed [4]. Good agreements were found between the measurements and the simulations of the final amount of the eutectic structure in $\mathrm{Al}-\mathrm{Cu}$ alloys processed by EML, thus identifying the role of the eutectic recalescence. Similarly, Kasperovich et al. applied different solidification techniques to study segregation in an $\mathrm{Al}-4 \mathrm{wt} \% \mathrm{Cu}$ alloy, including EML [7].

Analytical and numerical models for diffusion based segregation have been developed, a review of which can be found in Reference 1. Based on the work by Rappaz and Thévoz [8], Wang and Beckermann developed an analytical multiphase multiscale segregation model for both columnar and equiaxed solidification [9]. They succeeded to predict the effect of back diffusion in the solid at low cooling rate as well as the effect of dendrite tip undercooling at high cooling rate. This model was used by Martorano et al. [10] to study the columnar-to-equiaxed transition based on a solutal interaction mechanism between the two grain structures. The growth kinetics of the dendrite tips being a function of the local supersaturation of the extradendritic liquid, the velocity of the columnar structure was found to vanish upon growth of the equiaxed grains. Gandin et al. extended the segregation model by taking into account the nucleation and growth of the eutectic [4] and peritectic structures [11] while removing the assumption of a uniform composition of the interdendritic liquid, i.e. the liquid located inside the grain envelope that defines the mushy zone [11]. The estimation of the diffusion length in the extradendritic liquid (located outside the grain envelope) was approximated by an analytical formulation based upon a steady state 
assumption. Heringer et al. developed a numerical model for equiaxed growth, in which both heat and solute diffusions were numerically calculated [2]. However, diffusion in the solid was neglected and no solutal interaction was accounted for, the growth kinetics being only a function of the nominal composition of the alloy. A more sophisticated approach based on the Cellular Automaton (CA) - Finite Element (FE) model [12] was recently proposed by Guillemot el al. for the prediction of grain structure and segregation formed during solidification processes [13]. The heat and solute mass transfers at the scale of the ingot were modeled using the FE method. Coupling with the CA method permitted the integrations over time and space of the physical phenomena that govern solidification, such as the nucleation and growth of the primary dendritic solid phase and the grain movements. This was done at the scale of the cells defined by a regular square lattice or CA grid superimposed onto the static FE mesh. Its application yet remains limited by the use of a simple mass balance for each cell (lever rule approximation) when coupling with macrosegregation induced by natural convection due to buoyancy forces.

From the experimental viewpoint, EML is the technique used hereafter to study the effect of triggered nucleation on the solidification of $\mathrm{Al}-\mathrm{Cu}$ alloys. Metallurgical characterizations are performed to construct the distribution maps of the average composition of copper, the volume fraction of the eutectic structure and the dendrite arm spacing. Regarding numerical modeling, the development of a CAFE model is considered, with a native advanced segregation model integrated in each cell. A parametric study is achieved, that demonstrates the model capabilities compared to previous approaches to model solidification while accounting for the mass exchange with an extradendritic liquid. The model is then applied to the solidification of the $\mathrm{Al}-\mathrm{Cu}$ samples with spontaneous [4] and triggered nucleation.

\section{Experimental}

A detailed description of the EML technique can be found in Reference 14. Samples, with typically $0.2 \mathrm{~g}$ in mass, were prepared from pure $\mathrm{Al}(99.9999 \%)$ and $\mathrm{Cu}(99.999 \%)$. The compositions were selected as 4,14 and $24 \mathrm{wt} \% \mathrm{Cu}$ for later comparison with previous published work [4]. The magnetic field was used to levitate the sample under a low gas pressure of about 40-50 mbar He that was maintained during the whole solidification process. The levitated sample was then cooled by reducing the power of the magnetic field. Solidification was triggered by bringing an alumina plate into contact with the bottom surface of the droplet. Once solidified, the metal consisted of an approximately spherical volume with a diameter close to $5.3 \mathrm{~mm}$. During the experiments, temperature histories were recorded using a pyrometer located at the top of the levitated droplet, i.e. opposite to the triggering device with respect to the droplet. Precision with such a pyrometer is only $\pm 5 \mathrm{~K}$. Moreover, the temperature signal is affected by a noise which could 
be attributed to the translations and rotations of the levitated samples as well as to the pyrometer sensitivity. More details on the experimental procedure are given in Reference [4].

\section{Modeling}

The two dimensional (2D) FE method is used to solve the conservation equations for energy and solute mass averaged over a representative elementary volume containing a mushy zone, i.e. a mixture of the solid and liquid phases $[15,16]$. It is coupled with a CA method for the modeling of the solidification structure as originally proposed by Gandin and Rappaz [12, 13]. In this section, only extensions are presented, consisting of the use of an adaptive remeshing technique to compute macrosegregation at the scale of the FE mesh, a microsegregation model for the cells of the CA grid and a coupling scheme between the CA and the FE methods.

\section{Macroscopic heat and solute flows}

The solid and the liquid phases are assumed to have constant and equal densities. Hence in a pure diffusion regime, the average energy conservation can be written as follows:

\section{Erreur !}

where $\langle\mathrm{H}\rangle$ is the average enthalpy per unit volume, $\mathrm{T}$ is the temperature and $\mathrm{t}$ is the time. The average thermal conductivity, $\langle\kappa\rangle$, is taken as a constant in the following. Further assuming constant and equal values of the specific heat for the liquid and the solid phases, $\mathrm{C}_{\mathrm{p}}$, one can write $\langle\mathrm{H}\rangle=\mathrm{C}_{\mathrm{p}} \mathrm{T}+\mathrm{g}^{\mathrm{f}} \mathrm{L}$, where $\mathrm{L}$ denotes the latent heat of fusion per unit volume and $\mathrm{g}^{\mathrm{f}}$ is the volume fraction of the entire liquid phase. The average enthalpy is chosen as the primary unknown in Equation 1. The solution of this non-linear equation is obtained by using a Newton-Raphson procedure, which necessitates calculating the derivative $\partial \mathrm{H}_{\mathrm{n}} / \partial \mathrm{T}_{\mathrm{n}}$ at each node $\mathrm{n}$ of the FE mesh [16].

With a fixed solid and no liquid convection, the average conservation equation of a solute element writes [15]:

\section{Erreur !}

where $\langle w\rangle$ is the average composition of solute and $\left\langle w^{f}\right\rangle^{f}$ is the average composition of solute in the entire liquid phase. Diffusion in the solid phase is neglected at the scale of the FE mesh because the ratio of the diffusion coefficient in the solid phase, $\mathrm{D}^{\mathrm{s}}$, over the diffusion coefficient in the liquid phase, $\mathrm{D}^{1}$, is of the order of $10^{-3}$ for metallic alloys. The primary unknown considered in Equation 2 is the average composition of solute, $\langle w\rangle$. The average composition of the whole liquid 
phase is eliminated following the work by Prakash and Voller who introduced a split operator technique with an Euler backward scheme [17].

\section{Mesh adaptation}

The FE mesh adaptation approach initially proposed by Fortin [18] and developed by Alauzet and Frey [19] has been integrated in the FE method. It consists of a minimization method that evaluates the mesh size required to access a given error for a chosen field of the FE solution. The main idea is that the mesh size can be controlled by a directional error estimator based on the recovery of the second derivatives of the FE solution of the selected scalar field $[18,19,20]$. This strategy is known as the Hessian strategy. The Hessian, which is the tensor of the second spatial derivatives, can be computed for any scalar component of the FE solution. As shown in the previous references, this directional information can be converted into a mesh metric field which prescribes the desired element size and orientation to satisfy an objective prescribed error level. The implementation of this technique can be found in Reference 20. For the present application, the average composition was selected to track the solute field as well as to maintain the segregation pattern after completion of solidification. The Gruau and Coupez [21] unstructured and anisotropic mesh generator with adaptation has been used to generate the FE mesh.

\section{Solidification path}

Figure 1(a) gives a schematic presentation of the coupled CAFE model. The continuous domain is divided into a FE mesh using coarse triangles to solve the average conservation equations at the macroscopic scale. A regular lattice of fine squares defining the cells of the CA grid is superimposed onto the FE mesh. Each cell $v$ located in an element $F$ is uniquely defined by the

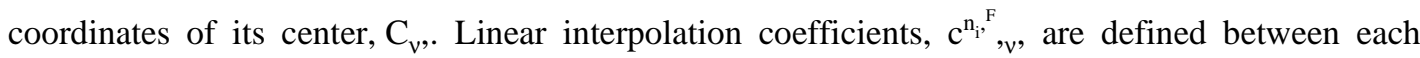
node $n_{i},{ }^{F}(i=[1,3])$ defining element $F$ and the cell $v$. A variable defined at the nodes, such as the average enthalpy $\left\{\left\langle\mathrm{H}_{n},\right\rangle\right\}$ or the average composition $\left\{\left\langle\mathrm{w}_{n},\right\rangle\right\}$, can thus be used to calculate an interpolated value at a given cell $v$, respectively $\left\langle\mathrm{H}_{v},\right\rangle$ or $\left\langle\mathrm{w}_{v},\right\rangle$. Similarly, information computed onto the CA grid can be projected onto the FE mesh. Nucleation and growth algorithms previously designed to track the development of the grain envelopes are used hereafter and will not be reviewed [13]. Upon cooling, when the nucleation undercooling prescribed in a cell $v$ is reached, an equilateral quadrangular surface is defined with its center $G_{,}$located at cell center $C_{,}$. An orientation $\theta$ with respect to the (x,y) frame of coordinates is then assigned to the cell, that defines the main growth directions of the dendritic structure, i.e. the $<10\rangle$ crystallographic directions for cubic metals. Illustration of such a growth shape is presented in Figure 1(b). The cell is then in a mushy state, i.e. formed by a mixture of the primary dendritic solid phase, $s$, and the interdendritic liquid phase, $\mathrm{d}$. The mushy zone volume fraction assigned to each cell $v, \mathrm{~g}^{\mathrm{m}}{ }_{{ }_{v}}=\mathrm{g}^{\mathrm{s}}{ }_{{ }_{v}}+\mathrm{g}^{\mathrm{d}}{ }_{v}$, is defined as the volume fraction of the solid phase $s, g^{s},{ }_{v}$, plus the interdendritic liquid phase $d, g^{d}{ }_{v}$. It is estimated by the half diagonal of the equilateral quadrangle divided by its maximum extension $R^{f}{ }_{v}$ 
$: \mathrm{g}^{\mathrm{m}}{ }_{\mathrm{v}}=\mathrm{R}^{\mathrm{e}}{ }_{{ }_{v}} / \mathrm{R}^{\mathrm{f}}{ }_{\mathrm{v}}$. The final radius associated to cell $\mathrm{v}, \mathrm{R}^{\mathrm{f}}{ }_{\mathrm{v}}$, is defined as the spatial limit for the growth of the equilateral quadrangular, which is of the order of several secondary arm spacings. In the case of a dendritic structure, this limit is chosen proportional to the primary dendrite arm spacing, $\mathrm{R}^{\mathrm{f}}{ }_{v}=\lambda_{1} / 2$. This distance depends on the local thermal gradient and can fluctuate during the solidification process. For the present study it is assumed constant and the same strategy is chosen for columnar and equiaxed grains.

The average enthalpy, $\left\langle\mathrm{H}_{\mathrm{n}}\right\rangle$, and solute composition, $\left\langle\mathrm{w}_{\mathrm{n}}\right\rangle$, at the FE node $\mathrm{n}$ being deduced from the solution of Equations 1 and 2, conversions are required into a temperature, $\mathrm{T}_{\mathrm{n}}$, and a fraction of solid, $\mathrm{g}^{\mathrm{s}}{ }_{\mathrm{n}}$. Instead of applying a solidification path at the FE nodes [15, 16], the conversions are first carried out for each CA cell $v$ to compute the temperature, $T_{,}$, and fraction of solid, $\mathrm{g}^{\mathrm{s}}{ }_{\mathrm{v}}$, from the interpolated enthalpy, $\left\langle\mathrm{H}_{\mathrm{v}}\right\rangle$, and average composition, $\left\langle\mathrm{w}_{\mathrm{v}}\right\rangle$. The fields at the CA cells are finally projected back to the FE nodes [13]. By definition and the use of equal and constant densities in all phases, one can write $\mathrm{g}^{\mathrm{s}}{ }_{{ }_{v}}+\mathrm{g}^{\mathrm{d}}{ }_{{ }_{\nu}}+\mathrm{g}^{1}{ }_{{ }_{v}}=1$ and

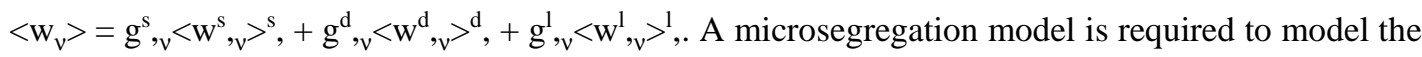
time evolution of the average volume fraction and composition of the solid phase $\mathrm{s}, \mathrm{g}^{\mathrm{s}}{ }_{{ }_{v}}\left\langle\mathrm{~W}^{\mathrm{s}},{ }_{v}\right\rangle^{\mathrm{s}}$, , the interdendritic liquid phase $\mathrm{d}, \mathrm{g}^{\mathrm{d}}{ }_{v}\left\langle\mathrm{w}^{\mathrm{d}},{ }_{v}{ }^{\mathrm{d}}{ }^{\mathrm{d}}\right.$, and the extradendritic liquid phase $1, \mathrm{~g}^{1}{ }_{v}\left\langle\mathrm{w}^{1},{ }_{v}{ }^{1}\right.$, . The corresponding mass balances are derived as an extension of the Wang and Beckermann analysis [9]. Mass exchanges are considered between the solid phase and the interdendritic liquid phase through the interfacial area concentration $\mathrm{S}^{\mathrm{sd}},{ }_{\mathrm{v}}$, as well as between the interdendritic liquid phase and the extradendritic liquid phase through the interfacial area concentration $\mathrm{S}^{\mathrm{ld}}{ }_{\mathrm{v}}$, while the mass between the solid phase and the extradendritic liquid phase is neglected:

Erreur $!=$ Erreur $!+$ Erreur $!$ Erreur $!$

Erreur ! = Erreur ! - Erreur ! - Erreur ! Erreur ! - Erreur ! Erreur ! + Erreur !

\section{Erreur $!=$ Erreur $!+$ Erreur $!$ Erreur $!+$ Erreur $!$}

where $\mathrm{w}^{\mathrm{sd}}{ }_{\mathrm{v}}$ is the average composition of the solid phase at the sd interface and $\mathrm{w}^{\mathrm{ld}}{ }_{\mathrm{v}}$ is the average composition of the liquid phases at the ld interface. Solute profiles are assumed in the solid phase and in the extradendritic liquid phase, respectively characterized by the diffusion lengths $1^{\mathrm{sd}}{ }_{v}$ and $1^{\text {ld }}, v$. The expressions for the interfacial area concentrations and the diffusion lengths, derived with the same assumptions as in the appendices of References 9 and 10, are provided in Table 1. Complete mixing of the interdendritic liquid composition and continuity of the composition at interface ld are assumed, $w^{\text {ld }}{ }_{, v}=\left\langle\mathrm{w}^{\mathrm{d}}{ }_{{ }_{v}}{ }{ }^{\mathrm{d}}\right.$, together with equilibrium at the sd interface. Thus, at temperature $T_{v}$, readings of the liquidus and solidus curves of the equilibrium phase diagram respectively give $\left\langle\mathrm{w}^{\mathrm{d}},{ }_{v}\right\rangle^{\mathrm{d}}$ and $\mathrm{w}^{\mathrm{sd}},{ }_{v}$. With $\mathrm{k}$ is the partition ratio, one can also write $\mathrm{w}^{\mathrm{sd}}{ }_{v}=\mathrm{k}\left\langle\mathrm{w}^{\mathrm{d}},{ }_{v}{ }^{\mathrm{d}}\right.$

For each phase $\alpha$, the time derivative of the volume fraction, $\partial \mathrm{g}^{\alpha}{ }_{\mathrm{v}} / \partial \mathrm{t}$, can be written as a function of the interfacial area concentration, $S^{\alpha \beta}{ }_{, v}$, and the normal velocity of the $\alpha \beta$ interface, $v^{\alpha \beta}{ }_{, v}$ , as $\mathrm{S}^{\alpha \beta}{ }_{, v} \mathrm{v}^{\alpha \beta}{ }_{, v}=\partial \mathrm{g}^{\alpha}{ }_{, v} / \partial \mathrm{t}=-\partial \mathrm{g}^{\beta}{ }_{\mathrm{v}} / \partial \mathrm{t}$ with $(\alpha, \beta)=\{(\mathrm{s}, \mathrm{d}),(1, \mathrm{~d})\}$. The volume fraction of the 
interdendritic liquid phase and the external liquid phase are respectively defined and computed as $\mathrm{g}^{\mathrm{d}}{ }_{\nu}=\mathrm{g}^{\mathrm{m}}{ }_{\nu}-\mathrm{g}^{\mathrm{s}},_{v}$ and $\mathrm{g}^{1}{ }_{\nu}=1-\mathrm{g}^{\mathrm{m}},{ }_{\nu}$. The growth rate of the mushy zone, $\partial \mathrm{g}^{\mathrm{m}}{ }_{v} / \partial \mathrm{t}$, is calculated with the growth rates of the half diagonal of the rhombus surface, $v^{\mathrm{e}}{ }_{v}=\partial \mathrm{R}^{\mathrm{e}}{ }_{\mathrm{v}} / \partial \mathrm{t}$. This is done assuming a dendrite tip growth kinetics model [24]:

Erreur ! = Erreur !

Erreur !

where $\Gamma$ is the Gibbs-Thomson coefficient, $\mathrm{Iv}^{-1}$ is the inverse of the Ivantsov function [23], $\sigma^{*}$ is a stability constant taken equal to $1 /\left(4 \pi^{2}\right)$ [24], $\Omega_{v}$ is the local supersaturation defined at the tip of a growing dendrite located at the growth front, i.e. between the mushy zone and the extradendritic liquid. The local supersaturation in Equation (7) is defined as the deviation of the liquid composition at the dendrite tip, $\mathrm{w}^{\mathrm{ls}}{ }_{\mathrm{v}}$, from the composition far away from the dendrite tip, Erreur !, i.e. in the extradendritic liquid, normalized by the composition jump between the liquid phase and the solid phase, $\mathrm{w}^{\mathrm{ls}}{ }_{v}(1-\mathrm{k})$. Further neglecting the curvature undercooling, the liquid composition at the dendrite tip can be approximated by the equilibrium composition, $\mathrm{w}^{\text {ld }}{ }_{\mathrm{v}}$. Dendrite tip models assume steady state growth of the microstructure in an undercooled liquid with an initial uniform composition taken equal to the nominal alloy composition, Erreur !. However, in order to account for the solutal interactions between grain boundaries, Wang and Beckermann and Martorano et al. choose to use the value of the liquid composition averaged over the extradendritic domain that remains in a predefined grain envelop, $\left\langle\mathrm{w}^{1}\right\rangle^{1}{ }_{\mathrm{D}}[9,10]$. Several strategies will be tested later for the determination of Erreur !.

The source terms in Equations (4) and (5), $\varphi,{ }^{\cdot \alpha}{ }_{, v}$ with $\alpha=\{\mathrm{d}, 1\}$, account for the solute mass exchange of the cell $v$ with its surrounding. According to the solute mass conservation written at the macroscopic scale, Equation (2), solute exchange between cells is only based on diffusion in the entire liquid $f$, i.e. through the interdendritic liquid phase $d$ and through the extradendritic liquid

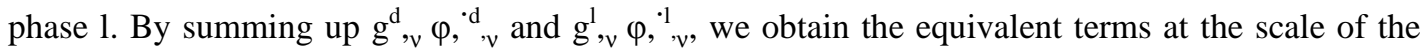
CA model of the solute diffusion term, $\nabla \cdot\left(\mathrm{g},{ }^{\mathrm{f}} \mathrm{D}^{\mathrm{l}} \nabla<\mathrm{w}^{\mathrm{f}},>^{\mathrm{f}}\right)$, computed by the FE model and interpolated at cell $v$. The relative portions, $\varphi,{ }_{, v}{ }_{v}$ and $\varphi,{ }^{\cdot d}$, can be quantified by introducing a partition ratio for diffusion in the liquid, $\varepsilon_{\mathrm{D}^{\mathrm{l}}}=\varphi,{ }_{,}{ }_{v} / \varphi,{ }_{,},{ }_{,}$. The following correlation is proposed as a function of the volume fraction of the interdendritic liquid phase and the extradendritic liquid phase: $\varepsilon_{\mathrm{D}^{1}}=\mathrm{g}^{1},_{v} /\left(\mathrm{g}^{1},_{v}+\mathrm{g}^{\mathrm{d}}{ }_{\nu}\right)$

Finally, the microsegregation model requires a local heat balance for cell $v$ :

\section{Erreur ! = Erreur ! - Erreur !}

Equations (3) to (8) constitute a complete system of differential equations with the four main unknowns $\left\langle\mathrm{w}^{\mathrm{s}},{ }_{v}\right\rangle^{\mathrm{s}}, \mathrm{g}^{\mathrm{s}}{ }_{v},\left\langle\mathrm{w}^{1}{ }_{v}\right\rangle^{1}$ and $\mathrm{T}_{v}$. A splitting scheme is applied to the differential equations, together with a first order Taylor series. An iterative algorithm is implemented to calculate the system solution. Once the prescribed growth temperature of the eutectic structure is reached, a 
simple isothermal transformation is assumed. Only Equation (8) is then solved considering no temperature variation over time and simply adjusting the fraction of solid with the variation of enthalpy up to completion of the solidification $[2,13]$.

\section{CAFE coupling scheme}

The main steps of the implemented coupling scheme are as follows:

sl-FE mesh and CA grid initializations. While the CA grid is fixed, the FE mesh is adapted as explained above. Based on the current FE tessellation, each cell $v$ is located inside a unique mesh $\mathrm{F}$ defined by its nodes $\mathrm{n}_{\mathrm{i}}, \mathrm{F}(\mathrm{i}=[1,3])$. This is done based on the position of the cell center $\mathrm{C}_{v}$. Subsequently, the linear interpolation coefficients $\mathrm{c}^{\mathrm{n}_{\mathrm{i}}{ }^{\mathrm{F}},{ }_{v}}$ are evaluated. All fields computed at the CA cells $v,\left\langle\xi_{v}\right\rangle$, are then projected to the FE nodes $n,\left\langle\xi_{n}\right\rangle$ [13]. This procedure is equivalent to a transport from the old mesh to the new one, but with the advantages to give more accuracy and to keep consistency between fields at the level of the two tessellations.

s2- FE solution. Equations 1 and 2 are solved, thus giving the fields at the $\mathrm{FE}$ nodes $\mathrm{n}$ for the average enthalpy, $\left\langle\mathrm{H}_{\mathrm{n}}\right\rangle$, and composition, $\left\langle\mathrm{w}_{\mathrm{n}}\right\rangle$.

s3-Interpolation onto the CA grid. This step permits the interpolation on the CA grid of the fields computed on the FE mesh, thus accessing to $\left\langle\mathrm{H}_{v}\right\rangle$ and $\left\langle\mathrm{w}_{v}\right\rangle$.

s4- CA calculations. Nucleation, growth and microsegregation of a dendritic mushy zone are simulated using Equations (3) to (8) to compute fields at the CA cells $v$ such as the average composition in the solid, $\left\langle\mathrm{w}^{\mathrm{s}},{ }_{v}\right\rangle^{\mathrm{s}}$, the volume fraction of solid, $\mathrm{g}^{\mathrm{s}}{ }_{\mathrm{v}}$, the average composition of the extradendritic liquid, $\left\langle\mathrm{w}^{1},_{v}\right\rangle^{1}$ and the temperature, $T_{v}$. The derivative, $\partial<\mathrm{H}_{v}>/ \partial \mathrm{T}_{v}$, is also computed.

s5-Projection onto the FE mesh. All fields at the CA cells are projected back onto the FE mesh.

s6- Loop on time steps. Achieved by going back to s1-.

\section{Comparison with literature}

This section presents simulations for $\mathrm{Al}-4 \mathrm{wt} \% \mathrm{Cu}$ and $\mathrm{Al}-10 \mathrm{wt} \% \mathrm{Cu}$ alloy alloys with the objective to conduct comparison with previous model developed for equiaxed solidification. The following approximations are considered:

a1-Geometry and nucleation. Simulations are carried out on a quarter disk geometry of radius $\mathrm{R}$ with axisymmetrical conditions with respect to its two perpendicular rectilinear edges. Location for nucleation of the primary solid structure is imposed at the corner of the simulation domain where the two perpendicular rectilinear edges intersect. 
a2- Heat transfer. Heat exchange on the spherical boundary of the droplet follows a global heat balance defined by an extraction rate, $\mathrm{q}_{\text {ext }}$. A Fourier boundary condition is assumed, defined by constant values for the heat transfer coefficient, $h_{\mathrm{ext}}$, and for the temperature, $\mathrm{T}_{\mathrm{ext}}$, such that $\mathrm{q} ;{ }_{\mathrm{ext}}=\mathrm{h}_{\mathrm{ext}}\left(\mathrm{T}-\mathrm{T}_{\mathrm{ext}}\right)$.

a3- Alloy. Linear monovariant lines of the phase diagram are assumed, that delimit the equilibrium domains of the mushy zone from the fully liquid and the fully solid ones. The phase diagram is thus defined the liquidus slope, $\mathrm{m}_{\mathrm{L}}$, the segregation coefficient, $\mathrm{k}$, the eutectic temperature, $\mathrm{T}_{\mathrm{E}}$, the eutectic composition, $\mathrm{w}_{\mathrm{E}}$, and the liquidus temperature of the alloys, $\mathrm{T}_{\mathrm{L}}$, for each alloy composition, $\mathrm{w}_{0}$.

a4- Nucleation undercooling. The nucleation undercooling of the primary solid structure, $\Delta \mathrm{T}_{\mathrm{N}}$, , and the eutectic structure, $\Delta \mathrm{T}_{\mathrm{N}}{ }^{\mathrm{E}}$, are respectively prescribed with respect to the liquidus temperature of the alloy, $\mathrm{T}_{\mathrm{L}}$, and the eutectic temperature, $\mathrm{T}_{\mathrm{N}}{ }^{\mathrm{E}}$.

a5- Growth. The grain is assumed to be spherical in shape. The growth rate is still calculated as a function of the supersaturation using Equations (6) and (7). In the following, Erreur ! will be taken equal to the average composition of the external liquid phase [9, 10], $\left\langle\mathrm{w}^{1}\right\rangle^{1}, \mathrm{D}$, the nominal composition of the alloy [2], $\mathrm{w}_{0}$, or the average composition of the cell [13], $\left\langle\mathrm{w}_{\mathrm{v}}\right\rangle$.

The first test case follows the study by Heringer et al. [2]. The simulation is carried out for a $250 \mu \mathrm{m}$ diameter droplet produced by impulse atomization of an $\mathrm{Al}-10 \mathrm{wt} \% \mathrm{Cu}$ alloy. Primary solidification is assumed to start $30 \mathrm{~K}$ below the liquidus temperature. The goal of the test is to compare the predicted composition profiles within the droplet. The mushy zone growth rate is thus computed with a supersaturation defined by the initial alloy composition, Erreur !=Erreur !, as was the case in Reference 2. A summary of the physical and numerical simulation parameters are listed in Table 2. Figure 2 shows the model predictions when the volume fraction of the mushy zone in the droplet reaches 0.64. The triangular elements are displayed in Figure 2(a), while the temperature, average solute composition and volume fraction of solid are displayed in Figure 2(b), 2(c) and 2(d), respectively. The location where the fraction of solid drops to zero is made accessible in Figure 2(b). It compares favorably with the position of the thick black line drawn on top of the FE mesh in Figure 2(a), the latter being deduced from the CAFE simulation by drawing the boundary between growing mushy cells and the liquid cells. Figure 2(c) reveals the sudden increase of the average composition in the vicinity of the grain envelope, due to the solute pile-up in the liquid ahead of the growth front. Comparison of Figure 2(a) with Figure 2(c) thus gives an illustration of the use of the second spatial derivatives of the average composition to adapt the FE mesh size. Figure 2(d) also gives access to the temperature field inside the droplet. While the maximum temperature variation only reaches a few degrees during the propagation of the mushy zone, it is also localized at the growing interface. This is due to the release of the latent heat at the grain envelope. The mushy zone is actually remelting due to the recalescence taking place at its 
boundary [2]. Finally, as shown in Figure 2(e), the present model retrieves the final segregation profile predicted by Heringer et al. [2]. Extended validation of the present CAFE model with respect to Heringer et al. [25] as well as with a front tracking model are presented elsewhere [26, 27], as well as an other illustration of the mesh adaptation [27].

The second test case is chosen to compare the model predictions with respect to simulations performed with a semi-analytical model for different final grain radius [10]. These simulations intend to illustrate the CAFE model capabilities to deal with mass exchange outside the grain envelope, as well as to study the effect of the solutal interaction for purely equiaxed growth as a function of the composition Erreur ! entering the definition of the growth front supersaturation in Equation (7). The effect of the final radius associated to cell $v, R^{f}{ }_{v}$, the control of which is provided by $\lambda_{1}$, is also studied as a model parameter. Results are presented in Figure 3 to 5 .

Figure 3 shows the time evolution of the mushy zone volume fraction of the grain, $\mathrm{g}^{\mathrm{m}}{ }_{\mathrm{D}}$, and the average internal volume fraction of solid in the envelope of the grain, $\mathrm{g}^{\mathrm{sm}}{ }_{\mathrm{D}}=\mathrm{g}^{\mathrm{s}},{ }_{\mathrm{D}} / \mathrm{g}^{\mathrm{m}} \cdot{ }_{\mathrm{D}}$, predicted by the CAFE model and the semi-analytical model [10]. The time scale has been normalized for all simulations by using the solidification time, i.e. $\$$. This representation permits comparison between systems of various sizes. In Figure 3(c1), Erreur !=Erreur ! and Erreur !=Erreur !, while the grain size is progressively increased from (11) $0.1 \mathrm{~mm}$ to (12) $1 \mathrm{~mm}$ and finally to (13) $10 \mathrm{~mm}$ $[9,10]$. Composition $\left\langle w^{1}\right\rangle^{1}, \mathrm{D}$ is calculated at a give time by a space integration of the average composition at each FE node over the fully liquid zone (i.e., the extradendritic liquid). For all calculations, no diffusion in the solid is considered and nucleation takes place at the liquidus temperature (no nucleation undercooling). When considering only Figure 3(c111) to 3(c113), one can observe a general agreement between the predictions of the semi-analytical model and the present numerical CAFE model. This is due to the use by the two models of the average composition of the extradendritic liquid, $\left\langle\mathrm{w}^{1}\right\rangle^{1}{ }_{\mathrm{D}}$, for the calculation of the supersaturation. However, while the deviation in Figure 3(c113) is found small for $\mathrm{R}=10 \mathrm{~mm}$, it does increase in Figure 3(c111) for $\mathrm{R}=0.1 \mathrm{~mm}$. In fact, for a smaller grain size, the interaction of the solute build-up ahead of the growing mushy zone with the boundary of the spherical domain starts very soon after nucleation, leading to a slower development of the mushy zone. This is shown by comparing $\mathrm{g}^{\mathrm{m}} \cdot \mathrm{D}$ in Figure 3(c111) and Figure 3(c113) as well as by the time evolution of $\left\langle\mathrm{w}^{1}\right\rangle_{, \mathrm{D}}^{1}$ drawn in Figure 5(c111). For the intermediate grain size, in Figure 3(c112), the solutal interaction takes place almost at the same time for the two simulations. However, the mushy zone predicted by the semi-analytical model never reaches unity, while the CAFE simulations succeed to this upper limit. It is also to be noted that the predictions of the present CAFE model systematically shows a different non monotonous behavior of $\mathrm{g}^{\mathrm{sm}}, \mathrm{D}$. The semi-analytical model first predicts a decrease follows by an increase of $\mathrm{g}^{\mathrm{sm}}{ }_{\mathrm{D}}$, thus leading to a single minima, while the CAFE model predicts two minima. The first minimum takes place just after nucleation and the second minimum almost corresponds in time and intensity to that predicted by the semi-analytical model. A similar behavior is found in Reference [2]. This difference is due to the isothermal approximation of the semi-analytical model, preventing the prediction of the first minimum. 
It is to be noticed that, while the use of Erreur $!=$ Erreur ! in the semi-analytical model is approximate; this quantity is not convenient for the evaluation of the supersaturation with the CAFE model. Indeed, it requires integrating over space the average composition at each FE node over a fully liquid zone whose shape and size needs to be arbitrary determine at each time step. For this reason, Guillemot et al. proposed to evaluate the supersaturation using Erreur !=Erreur ! [13]. The simulations corresponding to this practice are presented in Figure 3(c2) and Figure 5(c211) where results of the semi-analytical simulations are appended for comparisons. Similar deviations are found with respect to the semi-analytical simulations. However, one can observe that the second minimum on $\mathrm{g}^{\mathrm{sm}}{ }_{\mathrm{D}}$ only remains for the $10 \mathrm{~mm}$ grain radius and is suppressed for the two others. It is to be reminded that interpretation of this minimum was given as a global remelting taking place inside the grain envelope upon its development [2]. Thus, the present CAFE calculations show that, for a given grain size, such a global remelting also depends on the growth kinetics computed for the grain envelope. The remelting does not systematically take place as was explained earlier, depending not only on nucleation undercooling but also on grain size.

Calculations have finally been made to study the effect of the additional parameter introduced in the CAFE microsegregation model, i.e. the maximum extension of the mushy zone associated to a cell, $\mathrm{R}^{\mathrm{f}}{ }_{v}$, evaluated as the primary dendrite arm spacing, $\lambda_{1} / 2$. For that purpose, the primary dendrite arm spacing has arbitrarily been changed to $4 \lambda_{2}$ in Figure 4 and Figure 5(12), while still using (c1) Erreur !=Erreur ! and (c2) Erreur !=Erreur !. As for Figure 3, comparison with the semi-analytical model is made accessible. The main observation when comparing Figure 3(c1) with Figure 4(c1) is on the role of $\mathrm{R}^{\mathrm{f}}{ }_{\nu}$ with respect to the solutal interaction with the limit of the domain. The mushy zone reaches unity faster when increasing $\mathrm{R}_{{ }_{\mathrm{v}}}^{\mathrm{f}}$. This is linked to the composition of the extradendritic liquid at cell, $\left\langle\mathrm{w}_{, v}{ }_{,}\right\rangle^{1}$, that does increase later in the mushy zone for a larger value of $\mathrm{R}^{\mathrm{f}}{ }_{\mathrm{v}}$. So does the corresponding quantity at nodes, $\left\langle\mathrm{w}_{{ }_{\mathrm{n}}}{ }^{1}{ }^{1}\right.$, , and hence $\left\langle\mathrm{w}^{1}\right\rangle_{{ }_{\mathrm{D}}}{ }_{\mathrm{D}}$. The reason for using this second length scale parameter, $\mathrm{R}_{, v}^{\mathrm{f}}$, thus appears meaningful when considering the solutal interaction within the equiaxed dendritic microstructure. While between secondary dendrite arms a uniform composition field can be assumed, it is not the case between active secondary dendrite arms, i.e. between dendrite arms whose tips are located at the limit of the grain envelope. A second length scale defining this distance is thus required, that permit the control of the solutal interaction with the extradendritic liquid located outside the grain envelope. In fact, such a limited solutal interaction is nothing but that modeled upon columnar growth by Wang and Beckermann [9] where the primary dendrite arm spacing indeed plays the same role. Finally, comparing Figure 4(c2) with Figure 3(c2) and with Figure 4(c1), one can observe that an intermediate behavior is found when increasing $\mathrm{R}_{,}^{\mathrm{f}}$, and using Erreur !=Erreur !. At this stage, in-situ experimental measurements on single equiaxed growth while tracking the development of the solute build-up outside the grain envelope are missing to evaluate further the validity of the parameters proposed. In the following, all simulations are consequently conducted with parameters $\mathrm{R}^{\mathrm{f}}=\$$ and Erreur $!=$ Erreur $!$. 


\section{Results}

\section{Experimental}

The thick grey curves in Figure 6 presents the recorded cooling histories for the $\mathrm{Al}-\mathrm{Cu}$ samples solidified under electromagnetic levitation while triggering nucleation with an alumina plate. In the experimental cooling curves shown in Figure 6, comparison of the cooling rate prior to and after solidification clearly shows a large increase. In the liquid state (first part of recorded curves shown in Figure 6), cooling is controlled by convection of the He gas in the vicinity of the droplet surface. The alumina plate being entered into contact with the droplet plays the role of a heat sink and extracts heat by conduction. In fact, the first significant change of the cooling rate is observed at the time when the alumina plate is put into contact with the sample. This time coincides with the nucleation event of the primary structure, $t_{N},{ }_{s}$. But while the nucleation event is observed very close to the liquidus temperature, $\mathrm{T}_{\mathrm{L}}$, for the $\mathrm{Al}-4 \mathrm{wt} \% \mathrm{Cu}$ sample and the $\mathrm{Al}-14 \mathrm{wt} \% \mathrm{Cu}$ sample, a large nucleation undercooling is measured for the $\mathrm{Al}-24 \mathrm{wt} \% \mathrm{Cu}$ sample. The reason for the delayed nucleation is only due to the fact that the triggering device was brought to the levitated droplet later, while heat exchange by convection of the He gas had already undercooled the liquid.

The small plateaus below the eutectic temperature, $T_{E}$, observed in Figure 6(b) and 6(c) are the marker of a heat release, typical of the growth of the eutectic structure [24]. The nucleation and growth of the eutectic structure compensate the extraction of energy from the system. This is also verified by the increase in time of the plateau when increasing the initial copper composition, $\mathrm{w}_{0}$. The duration of the plateau is indeed proportional to the amount of eutectic measured in the solidified state, $\mathrm{g}_{\mathrm{D}}{ }^{\mathrm{E}}$, reported in Table 3. For the $\mathrm{Al}-4 \mathrm{wt} \% \mathrm{Cu}$ sample, no plateau is found in Figure 6(a) below $T_{E}$ because the fraction of eutectic is too small. The times for the beginning of these plateaus are labeled $t_{N},{ }^{E}$ in Figure 6. Therefore, the temperatures measured at times $t_{N},{ }^{s}$ and $\mathrm{t}_{\mathrm{N}}{ }^{\mathrm{E}}$, respectively $\mathrm{T}_{\mathrm{N}},{ }^{\mathrm{s}}$, and $\mathrm{T}_{\mathrm{N}}{ }^{\mathrm{E}}$, also correspond to the nucleation temperature of the dendritic and eutectic structures. Additional information is extracted from the cooling curves and listed in Table 3, such as the nucleation undercooling for the primary dendritic and the eutectic structures, respectively $\Delta \mathrm{T}_{\mathrm{N}},{ }^{\mathrm{s}}=\mathrm{T}_{\mathrm{L}}-\mathrm{T}_{\mathrm{N}},{ }^{\mathrm{s}}$, and $\Delta \mathrm{T}_{\mathrm{N}},{ }^{\mathrm{E}}=\mathrm{T}_{\mathrm{E}}-\mathrm{T}_{\mathrm{N}},{ }^{\mathrm{E}}$. Note that because of the low precision of the measurement, the nucleation undercoolings for the $\mathrm{Al}-4 \mathrm{wt} \% \mathrm{Cu}$ sample and the $\mathrm{Al}-14 \mathrm{wt} \% \mathrm{Cu}$ sample are set to 0 in Table 3 . The time for the end of solidification, $t_{\text {end }}$, could also be estimate from Figure 6 as the last characteristic time at which a significant slope change is observed in the cooling curve. For the $\mathrm{Al}-4 \mathrm{wt} \% \mathrm{Cu}$, the end of the solidification is defined as the time where the recorded temperature is below the equilibrium eutectic temperature, $T_{E}$, since the small fraction of eutectic prevents a clear signal on the cooling curve and thus a slope change. Other measurements on each curve are the cooling rates just before and after the end of the solidification, respectively $\mathrm{T},\left(\mathrm{t}<\mathrm{t}_{\mathrm{N}},{ }^{\mathrm{s}}\right)$ and $\mathrm{T},\left(\mathrm{t}>\mathrm{t}_{\mathrm{end}},\right)$ listed in Table 3. 
For all samples, the first nucleation event is followed by a temperature increase. While the same trend is observed for samples solidified upon spontaneous nucleation, the magnitude and shape is very different. Indeed, experimental data reported earlier for the same alloys but with no triggering lead to larger nucleation undercooling and sudden recalescences measured for both the primary dendritic and the secondary eutectic microstructures [4]. The reason is linked to the absence of a heat sink when no triggering device is used, thus permitting the system to adopt an almost uniform temperature and to have an extraction rate only defined by convection of the $\mathrm{He}$ gas. The growth of the microstructure is accompanied by a rapid increase of the temperature measured by the pyrometer, that corresponds to a global recalescence of the system. All parameters listed in Table 3 are also provided for the samples solidified under spontaneous nucleation [4]. Hence, in the case of triggered nucleation, two conditions of heat extraction jointly coexist after the contact with the alumina plate, which are linked to the convection of the gas at the almost entire surface of the droplet and conduction through the small surface of the triggering device into contact with the droplet, leading the cooling curves displayed in Figure 6. Further interpretation thus requires modeling of the heat flow in the entire droplet, with is presented later on in this presentation.

Experimental measurements also consist of the distribution of copper on the meridian cross section of the droplets. In addition, analyses were conducted on images produced by SEM [4, 28] in order to reveal the distribution of the eutectic volume fraction and the dendrite arm spacing (DAS) in the same cross sections. Global averaging over the entire measurements for each sample leads to the values listed in Table 4 for the copper content, $\mathrm{w}_{\mathrm{D}}$, the eutectic volume fraction, $\mathrm{g}_{\mathrm{D}}^{\mathrm{E}}$, and the dendrite arm spacing, $\mathrm{DAS}_{\mathrm{D}}$, respectively. The average copper content, $\mathrm{w}_{\mathrm{D}}$, shows a deviation from the nominal composition, $\left(\mathrm{w}_{\mathrm{D}}-\mathrm{w}_{0}\right) / \mathrm{w}_{0}$, that varies from $-8.37 \%$ for the $24 \mathrm{wt} \% \mathrm{Cu}$ to $+9.25 \%$ for the $4 \mathrm{wt} \% \mathrm{Cu}$. As explained previously, these deviations are expected to result from a non-symmetric growth of the dendritic structure within a plane or an axis defined with respect to the analyzed central meridian cross sections [4]. The average eutectic volume fraction over the entire section plane, $\mathrm{g}_{\mathrm{D}}{ }^{\mathrm{E}}$, is closer to the prediction $\mathrm{g}_{\mathrm{GS}},{ }^{\mathrm{E}}$ of the Gulliver-Scheil model considering the initial composition, $\mathrm{w}_{0}$, when comparing the triggered nucleation samples. This could be partly explained by the short solidification times for the triggered samples compared to spontaneous nucleation. Hence, solute diffusion in the solid is not expected to influence the final amount of eutectic structure for such short solidification times. In addition, no recalescence has been measured for the eutectic structure that would have lead to an increase of the eutectic fraction by partial remelting the already existing dendritic structure as was shown for spontaneous nucleation [4].

Figure 7(c1) presents the results of the normalized distribution maps of the average $\mathrm{Cu}$ content, $\langle w\rangle$, for measurements conducted on a regular square lattice of $120 \cdot 10^{-6} \mathrm{~m} \times 150 \cdot 10^{-6} \mathrm{~m}$ local surfaces. Normalization is achieved with respect to the initial composition using $\left(\langle\mathrm{w}\rangle-\mathrm{w}_{0}\right) / \mathrm{w}_{0}$. Macrosegregations at the scale of the surfaces analyzed are thus identified by regions with negative or positive deviations with respect to the nominal composition, $\mathrm{w}_{0}$. The normalized distribution maps drawn for the average volume fraction of the eutectic structure deduced from image analyses, 
$\left\langle\mathrm{g},{ }^{\mathrm{E}}\right\rangle$, are shown in Figure 7(c2). Normalization is achieved following the work of Sarreal and Abbaschian [29], i.e. using the value of the volume fraction of the eutectic structure predicted by the Gulliver-Scheil approximation for each alloy, $\mathrm{g}_{\mathrm{GS}}{ }^{\mathrm{E}}$, the value of which are listed in Table 4 for each alloy. Finally, the distributions of the average dendrite arm spacing, $\langle$ DAS $\rangle$, are given in Figure 7(c3). Measurements are conducted using the same images and averaging surfaces as for the average fraction of eutectic. Similarly to what has been previously reported for spontaneous nucleation [4], a strong correlation is found for the $\mathrm{Al}-4 \mathrm{wt} \% \mathrm{Cu}$ alloy. To a positive deviation of the average composition in Figure 7(c111) corresponds a positive deviation of the average fraction of eutectic in Figure 7(c112) and a finer microstructure in Figure 7(c113). This general trend was also found for the $\mathrm{Al}-14 \mathrm{wt} \% \mathrm{Cu}$ and $\mathrm{Al}-24 \mathrm{wt} \% \mathrm{Cu}$ alloys solidified upon spontaneous nucleation. However, while such a dependence is not as clear for the $\mathrm{Al}-14 \mathrm{wt} \% \mathrm{Cu}$ sample presented in Figure 7(12), it is not anymore valid when increasing the alloy composition and considering the $\mathrm{Al}-24 \mathrm{wt} \% \mathrm{Cu}$ sample in Figure 7(13). While the positive deviation of the average fraction of eutectic in Figure 7(c213) corresponds to a finer microstructure in Figure 7(c313) close to the nucleation area, a negative macrosegregation is found in the same zone. Further interpretations are now given based on direct simulations of the solidification experiments.

\section{Simulations}

Approximations for the simulations are modified with respect to previous simulations as follows, $a 3$ - and $a 4$ - being kept unchanged:

a1- Geometry and nucleation. Simulations are carried out on half disk geometry of radius $\mathrm{R}$ with an axisymmetrical condition with respect to the rectilinear edge of length $2 \mathrm{R}$. Location for nucleation is imposed at the bottom of the simulation domain, i.e. at the south pole in Figure 8(c111) where the triggering device enters into contact with the droplet surface (A').

a2- Heat transfer. In order to model the heat exchange for triggered samples, the total boundary of the domain is divided into two parts, $\mathrm{A}$ and $\mathrm{A}^{\prime}$, where distinct time-dependent heat transfer conditions are defined. $\mathrm{A}^{\prime}$ is nothing but the contact area between the droplet and the alumina plate, while A represents the rest of the droplet surface. The configuration is applied for all calculations and is schematized in Figure 8(c111). Fourier boundary conditions are assumed, defined by two values of the heat transfer coefficients related to the $A$ and $A^{\prime}$ external boundaries, $h_{\text {ext }},{ }^{A}(t)$ and $h_{\text {ext }},{ }^{A^{\prime}}(t)$ , and temperature, $\mathrm{T}_{\text {ext }}$, such that $\mathrm{q} ;{ }_{\text {ext }}{ }^{\prime}=\mathrm{h}_{\text {ext }},{ }^{\mathrm{A}}\left(\left.\mathrm{T}\right|_{\mathrm{A}}-\mathrm{T}_{\text {ext }}\right)+\mathrm{h}_{\text {ext }},{ }^{\mathrm{A}^{\prime}}(\mathrm{t})\left(\left.\mathrm{T}\right|_{\mathrm{A}^{\prime}}-\mathrm{T}_{\text {ext }}\right)$, with $\left.\mathrm{T}\right|_{\mathrm{A}}$ and $\left.T\right|_{A^{\prime}}$ the temperature fields at the various location of the boundaries defined by $A$ and $A^{\prime}$. Prior to the nucleation of the primary phase, $h_{e x t}{ }^{A^{\prime}}(t)$ is taken equal to $h_{e x t},{ }^{A}$ and the boundary condition is thus similar to that used for spontaneous nucleation. Its adjustment is based on the cooling rates measured prior to the primary phase nucleation, $\mathrm{T},\left(\mathrm{t}<\mathrm{t}_{\mathrm{N}},{ }^{\mathrm{S}}\right)$ [4]. While $h_{\text {ext, }}{ }^{A}$ is maintained constant after nucleation, the heat transfer coefficient 
between the alumina plate and the fully solid droplet is adjusted by assuming that $h_{e x t}, A^{\prime}\left(t>t_{e n d}\right)$ is representative of the heat flow from the time of nucleation, $h_{\text {ext }}, A^{\prime}\left(t>t_{N},{ }^{s}\right)$ $=h_{\text {ext }}, A^{\prime}\left(t>t_{\text {end }}\right)$. A single value could be used for the simulation of all droplets. After nucleation, $h_{\text {ext }}, A^{\prime}(t)$ is thus abruptly increased from $h_{e x t}, A^{\prime}\left(t<t_{N},{ }^{s}\right)$ to $h_{e x t}, A^{\prime}\left(t>t_{N},{ }^{s}\right)$. The fitted values $\mathrm{h}_{\mathrm{ext}},{ }^{\mathrm{A}}, \mathrm{h}_{\mathrm{ext}}, \mathrm{A}^{\prime}\left(\mathrm{t}<\mathrm{t}_{\mathrm{N}},{ }^{\mathrm{s}}\right)$ and $\mathrm{h}_{\mathrm{ext}}, \mathrm{A}^{\prime}\left(\mathrm{t}>\mathrm{t}_{\mathrm{N}},{ }^{\mathrm{s}}\right)$ are listed in Table 2.

a5- Growth. The standard growth algorithm of the CA model is used [13], thus not considering an arbitrarily spherical shape for the grain envelope. The growth rate is calculated as a function of the supersaturation using Equations (6) and (7) with Erreur != $\left\langle\mathrm{w}_{\mathrm{v}}\right\rangle$.

All data for the simulations are listed in Table 2 and 3. The present model has first been applied to the solidification experiments with spontaneous nucleation yet assuming no nucleation undercooling for the eutectic structure [4]. Only the results in terms of the final global amount of eutectic are reported in Table 4 as $\mathrm{g}_{\mathrm{CAFE}}{ }^{\mathrm{E}}=6.8 \%$ for the $\mathrm{Al}-4 \mathrm{wt} \% \mathrm{Cu}, \mathrm{g}_{\mathrm{CAFE}}{ }^{\mathrm{E}}=33.48 \%$ for the $\mathrm{Al}-14 \mathrm{wt} \% \mathrm{Cu}$ and $\mathrm{g}_{\mathrm{CAFE}}{ }^{\mathrm{E}}=67 \%$ for the $\mathrm{Al}-24 \mathrm{wt} \% \mathrm{Cu}$. These predictions are very close to the results of the simulations presented earlier with the semi-analytical model when an isothermal transformation is assumed to occur at the eutectic temperature (values in c212, c216 and c2110 in Table 6 of Reference 4 are provided in normalized fraction of eutectic, $\mathrm{g}^{\mathrm{e}} / \mathrm{g}_{\mathrm{GS}}{ }^{\mathrm{e}}$, equivalent to $\mathrm{g}^{\mathrm{E}}$, $/ \mathrm{g}_{\mathrm{GS}}{ }^{\mathrm{E}}$, with the notations of the present contribution): $\mathrm{g},{ }^{\mathrm{e}} / \mathrm{g}_{\mathrm{GS}},{ }^{\mathrm{e}}=0.72$ for the $\mathrm{Al}-4 \mathrm{wt} \% \mathrm{Cu}, \mathrm{g},{ }^{\mathrm{e}} / \mathrm{g}_{\mathrm{GS}}$, $=0.81$ for the $\mathrm{Al}-14 \mathrm{wt} \% \mathrm{Cu}$ and $\mathrm{g}^{\mathrm{e}}, \mathrm{g}_{\mathrm{GS}}{ }^{\mathrm{e}}=0.71$ for the $\mathrm{Al}-24 \mathrm{wt} \% \mathrm{Cu}$. But these predictions deviate from the measurements also given in Table $4, \mathrm{~g}_{\mathrm{D}},{ }^{\mathrm{E}}$. These deviations were explained by the role of the nucleation undercooling and the recalescence associated with the eutectic microstructure, which can not be neglected for the prediction of the final as-solidified state [4]. The present CAFE simulations thus provide a new validation of the numerical model compared with a semi-analytical model [4], but at the same time clearly identify its limitation for the prediction of the phase fractions when nucleation undercooling and possible recalescence of secondary phases occur. Implementation of the nucleation and growth of secondary microstructures forming mainly in an interdendritic liquid but also possibly in the extradendritic liquid would thus be justified in order to improve the present CAFE model.

Figure 6 compares the predicted cooling to the measurements for the three $\mathrm{Al}-\mathrm{Cu}$ samples. The thin black plain curves correspond to the temperature averaged over the entire simulation domain, $\mathrm{T}_{\mathrm{D}}$, while the thin black curves with upward triangles $\boldsymbol{\Delta},-$ and downward triangles $\boldsymbol{\nabla}$, are the temperature at the north and south poles of the simulation domain, respectively $\mathrm{T}_{\mathrm{NP}}$, and $\mathrm{T}_{\mathrm{SP}}$, . During the initial cooling in the liquid state $\left(\mathrm{t}<\mathrm{t}_{\mathrm{N}},{ }^{\mathrm{s}}\right)$, the predicted cooling rate is almost constant and reproduces well the recorded temperature histories. This is possible thanks to the adjustment of the same parameters of the Fourier boundary condition applying on A and $\mathrm{A}^{\prime}$ before $\mathrm{t}_{\mathrm{N}}{ }^{\mathrm{s}}$. At the time when the nucleation undercooling is reached, sharp changes on the predicted cooling rate starts at the nucleation point as clearly revealed by $\mathrm{T}_{\mathrm{SP}}$. Again, the increase of the cooling rate is due to the adjustment of the parameters on $\mathrm{A}^{\prime}$, thus simulating the contact of the triggering device on the 
droplet. Very soon after this nucleation event at the south pole, a temperature increase is computed at the north pole, $\mathrm{T}_{\mathrm{NP}}$. This evolution is comparable with the temperature evolution recorded by the pyrometer seeing the top surface of the droplet. Consideration of the three simulated temperatures for each sample also shows a clear non-uniform cooling due to the role of the triggering device that almost serves as a chill. The effect is also very clear when considering the systematic increase of the DAS from the south pole to the north pole displayed in Figure 7(c3). Also of interest is the large deviation of the average predicted temperature, $\mathrm{T}_{\mathrm{D}}$, from the recorded cooling history. On the contrary to the situation of spontaneous nucleation, interpretation of the measured temperature evolution requires the use of the present non-isothermal model.

A eutectic plateau is predicted by the model on the cooling curves in Figure 6(b) and 6(c). The length of the plateau varies increases with the alloy composition as previously explained since it is proportional to the final amount of eutectic. This results is in line with the experimental observations. The predicted average eutectic volume fractions, $\mathrm{g}_{\mathrm{CAFE}}{ }^{\mathrm{E}}$, are listed in Table 4 together with the measured values $\mathrm{g}_{\mathrm{D}}$, . These values are close to the Gulliver-Scheil model predictions $\mathrm{g}_{\mathrm{GS}},{ }^{\mathrm{E}}$ . Again, this can be explained by the short solidification time and the high heat extraction rate through the trigger, leading to a small effect of solid diffusion. However, it should be noted that for the $\mathrm{Al}-24 \mathrm{wt} \% \mathrm{Cu}$ sample, the final amount of eutectic can only be retrieved if one account for the measured undercooling prior to the nucleation, $\Delta \mathrm{T}_{\mathrm{N}}{ }^{\mathrm{E}}=20 \mathrm{~K}$ (Table 3), leading to the value $\mathrm{g}_{\mathrm{CAFE}}$, $=65 \%$, i.e. close to measured value $\mathrm{g}_{\mathrm{D}}{ }^{\mathrm{E}}=61.62 \%$. Model prediction increase up to $\mathrm{g}_{\mathrm{CAFE}},{ }^{\mathrm{E}}$ $=81.4 \%$ when the simulation is run with an isothermal eutectic transformation at the eutectic temperature, $\mathrm{T}_{\mathrm{E}}$, i.e. with no nucleation undercooling.

For a given alloy composition, consideration on microsegregation modeling accounting only for diffusion in the solid phase and complete mixing in the liquid predicts more eutectic in location where the Fourier number for the solid phase is smaller. With a Fourier number equal to zero, such microsegregation approach retrieves the result of the Gulliver-Scheil approximation. The Fourier number is proportional to the diffusion in the solid phase and the solidification time and inversely proportional to the square of the characteristic DAS. A higher fraction of eutectic is thus expected at the south pole where the solidification time is the lowest and the DAS the smallest. This is for instance observed on the $\mathrm{Al}-24 \mathrm{wt} \% \mathrm{Cu}$ sample. However, solute diffusion in the solid phase is not sufficient for the interpretation of the present results. Not only the average composition of the alloy is not constant as shown in Figure 7(c1), but also no sign of the eutectic transformation is present on $\mathrm{T}_{\mathrm{SP}}$, as shown in Figure 6(c). Evaluation of the magnitude of the Fourier number for such high cooling rate also reveals that solid diffusion is very unlikely to play a significant role. Consequently, one has to conduct a more thorough examination of the experimental observations in light of the CAFE in order to account for diffusion in the solid and liquid phases, the non uniform temperature as well as the nucleation undercooling.

Figure 8 summarizes the model predictions for the normalized average copper composition, $\left(<\mathrm{w}>-\mathrm{w}_{0}\right) / \mathrm{w}_{0}$, and the eutectic volume fraction, $\left(\mathrm{g},{ }^{\mathrm{E}}-\mathrm{g}_{\mathrm{GS}}{ }^{\mathrm{E}}\right) / \mathrm{g}_{\mathrm{GS}} \mathrm{E}$. The same scales as for the 
representation of the measured maps (Figure 7(c1) and 7(c2)) are chosen. No map is provided for the DAS since the CAFE model is still limited by the use of a uniform value over the simulation domain. For the simulations of Figure 8, the average values listed in Table 3 measured over the entire experimental cross sections, $\mathrm{DAS}_{\mathrm{D}}$, are used. It should be recalled that a direct comparison with the experimental results in Figure 7 is not possible since there is no attempt to exactly reproduce the dendritic grain structure (as was the case for instance in reference 13). The overall variations of the distributions are yet retrieved by the model and can thus be used hereafter.

The first observation is that the magnitude of the segregation is less than the measured for each alloy. However, it should be noted that the normalizations have been achieved using the nominal composition of the sample 4, 14 and $24 \mathrm{wt} \%$. As the measured average copper content over the cross section listed in Table 3 are respectively 4.37, 13.81 and $21.99 \mathrm{wt} \%$. For the triggered $\mathrm{Al}-$ $4 \%$ wt $\mathrm{Cu}$ sample, the correlation between the distribution map of copper and the eutectic fraction found in Figure 7(11) are retrieved on simulated maps presented in Figure 8(11). Because the eutectic transformation is modeled with no eutectic undercooling, the remaining liquid at $T_{E}$ that transforms into eutectic only depends on the average local composition and the effect of diffusion in the solid. But the latter effect is small for the triggered samples as explained above. Consequently, less eutectic is found in the region of lower average copper content, typical of the result know from classical microsegregation analyses when decreasing the alloy composition. The question then rises on the reason for a lower average composition, that is explained by diffusion of species from the mushy zone toward the extradendritic liquid, as well as inside the mushy zone due to the temperature gradient that create a gradient of the interdendritic liquid composition. Thus, diffusion in the liquid is a key phenomenon to account for in order to give an adequate interpretation of the present observations.

The case of $\mathrm{Al}-24 \mathrm{wt} \% \mathrm{Cu}$ is not as straightforward to explain. As mentioned previously, more eutectic is found at the bottom of the sample where the average composition is only slightly lower than elsewhere in the sample (Figure 7(13)), which is thus opposite to the observation for the $\mathrm{Al}-4 \mathrm{wt} \% \mathrm{Cu}$. The simulation in Figure 8(13) shows a similar trend as the experimental observations and can thus be analyzed into more details. While diffusion of $\mathrm{Cu}$ outside the mushy zone is still accounted for, it does only slightly change the amount of solute at the bottom of the sample. In fact, a quenching mechanism is rather observed. As shown in Figure 6(c), the bottom part of the sample becomes fully solid (its temperature decreases below $T_{E}-\Delta T_{E}$ ) in only a fraction of second after primary nucleation of the dendritic phase. Because a large nucleation undercooling was used for the primary solid, a small fraction of solid was formed prior to nucleate and grow the interdendritic liquid. In other words, the bottom part of the sample underwent phase transformations with a large deviation from the initial and final temperatures defined by the equilibrium solidification interval. Such a quenching is not observed in the $\mathrm{Al}-4 \mathrm{wt} \% \mathrm{Cu}$ sample for several reasons. At first, solidification started close to the liquidus temperature and the solidification interval is larger compared to $\mathrm{Al}-24 \mathrm{wt} \% \mathrm{Cu}$. As a consequence, the release of latent heat prevents fast cooling of the bottom part of the system below the temperature at which the eutectic 
transformation takes place. The intermediate situation found with the $\mathrm{Al}-14 \mathrm{wt} \% \mathrm{Cu}$ sample is interesting to analyze. With a nucleation event also close to the liquidus temperature of the alloy, the solidification interval is smaller and hence solidification takes place in less than 1 second. Small variations of the eutectic fraction are found in the distribution maps of Figure 7(c212) and Figure 8(c212). However, while little variations of the $\mathrm{Cu}$ distribution are simulated in Figure 8(c112), measurements reveal a significant gradient of the average composition, almost monotonous from high content at the bottom to low content the top. It is believed that inverse segregation thus also plays a role [30], revealed when no large nucleation undercooling is achieved and the solidification interface is sufficiently large. Although the present model is capable to deal with macrosegegation influenced by fluid flow as shown elsewhere [27], it is no yet coupled with a general thermomechanical calculation $[31,32]$. To account for this phenomena, a variation of the density of alloy with the fraction of the phases is required. Even with fixed solid considering a constant density of the solid phase and potentially no thermomechanical deformation, the total volume of the simulation domain must be adapted by tracking the interface between the liquid and the gas, which is not yet available with the present CAFE model.

\section{Conclusions}

The findings of the experimental and numerical studies are summarized below:

- Al-Cu alloys systems have been solidified using EML technique with compositions 4, 14 and $24 \mathrm{wt} \% \mathrm{Cu}$. Samples are approximately spherical in shape with a radius of $2.65 \cdot 10^{-3} \mathrm{~m}$. The nucleation of the primary phase has been initiated using an alumina plate at the lower surface for each sample. Non-equilibrium temperature histories have been recorded using an optical pyrometer. Important heat loss is found to take place through the trigger from the south pole of the droplets. The local $\mathrm{Cu}$ content together with the eutectic volume fraction and the DAS have been measured. The normalized distribution maps reveal macrosegregation at the scale of the droplet and monotonous increase of the DAS from the south pole to the north pole. These data, averaged over the entire metallographic cross sections, gives value that can be compared with those previously obtained for spontaneously solidified samples [4].

- An advanced microsegregation model has been embedded in a 2D CAFE model together with a mesh adaptation technique. The new model could be seen as an extension of previous CAFE modeling in two main directions: $i$ - the scale CA model accounts for diffusion in the solid and liquid phases together with the nucleation and growth undercooling of the primary solid phase, and $i i$ - the FE method solves solute diffusion in the liquid in front of the mushy/liquid interface over an adaptive mesh depending on the local solute profile. Extensive validations of the model have been conducted showing its capability to deal with solute diffusion inside and outside a growing mushy zone. 
- Applications of the CAFE model to the solidification of the processed Al-Cu droplet have been achieved. The predicted temperature curves give a coherent explanation of the measured temperature evolutions (Figure 6). Although the magnitudes of the simulated average composition and eutectic maps (Figure 8) show a deviation from the measurements, the model is successively used to interpret the experimental observations. Diffusion in the solid is identified to have a minor effect compared to diffusion in the liquid. As for spontaneously solidified samples, the nucleation undercooling of the secondary eutectic phase is found to play a major role.

- Limitations of the CAFE model are also found, such as the absence of a coarsening model to be embedded in the CA microsegregation model, and the possibility to account for the nucleation and growth of secondary microstructures such as eutectics. Similarly, laboratory scale experiments are required in order to quantify the solutal interaction between grains. This would ideally benefit from in-situ measurements using synchrotron radiation facility.

\section{Acknowledgments}

This work was conducted within a European Space Agency project of the Microgravity Applications Promotion program (contract 15236/02/NL/SH). Contributions from S. Jacomet, B. Triger and M. Repoux are acknowledged. Samples were processed using electromagnetic levitation by Th. Volkmann and D. Herlach at the Deutsches Zentrum für Luft- und Raumfahrt e.V. (DLR), Köln, Germany. 


\section{References}

[1] Beckermann C., Int. Mater. Rev. 47 (2002); 243:261.

[2] Heringer R., Gandin Ch.-A., Lesoult G., Henein H. Acta Materialia (2006); 54:4427.

[3] Prasad A., Henein H., and Conlon K.T., Met. Trans. A, v.37, n.5 (2006); 1589:96.

[4] Prasad A., Henein H., Mosbah S., Gandin Ch.-A., ISIJ International (2009) in press.

[5] Gandin Ch.-A., Mosbah S., Volkmann Th., Herlach D.M. Acta Materialia (2008); 56:3023.

[6] Herlach D. M., Annual Review of Materials (1991); 21:23.

[7] Kasperovich G., Volkmann T., Ratke L., and Herlach D. Met. Tran. A. (2008); 39:1183.

[8] Rappaz M., Thévoz Ph. Acta Metallurgica (1987); 35:2929.

[9] Wang C. Y., Beckermann C. Metall. trans. A. (1993); 24:2787.

[10] Martorano M.A., Beckermann C., Gandin Ch.-A. Metall. mater. trans. 34A. (2003); 1657.

[11] Tourret D., Gandin Ch.-A., Acta mater. 57 (2009) 2066:79.

[12] Gandin Ch.-A., Rappaz M., Acta metall. 42 (1994) 2233:46.

[13] Guillemot G., Gandin Ch. -A., Bellet M. Journal of Crystal Growth (2007); 303:58.

[14] Herlach D., Galenko P., and Holland-Moritz D. Metastable Solids from Undercooled Melts, First edition, Pergamon Materials Series, Germany (2007).

[15] Bellet M., Fachinotti V.D., Gouttebroze S., Liu W., Combeau H., in Solidification Processes and Microstructures: A Symposium in Honor of Prof. W. Kurz, Eds M. Rappaz, C. Beckermann, R. Trivedi, TMS, Warrendale, United States of America (2004); 15:26.

[16] Liu W., Finite element modelling of macrosegregation and thermomechanical phenomena in solidification processes, Ph. D. Thesis, Ecole Nationale Supérieure des Mines de Paris, Paris, France (2005).

[17] Prakash C. , Voller V., Numerical Heat Transfer 15B (1989);171:189.

[18] M. Fortin, Estimation d'erreur a posteriori et adaptation de maillages, Revue Européenne des Eléments Finis 9 (2000);467:486

[19] Alauzet F., Frey P.J. Rapport de Recherche INRIA Mars N 4759 (2003).

[20] Hamide M., Massoni E., Bellet M., Int J. Num Meth. Eng. (2008); 73:624.

[21] Gruau C., Coupez T., Computer Methods Appl. Mech. Engrg. (2005); 194:4951.

[22] Guillemot G., Formation de structures de grains dans des alliages à solidification dendritique - modélisation couplée automates cellulaires et eléments finis, $\mathrm{Ph}$. D. Thesis, Institut National Polytechnique de Lorraine, Nancy, France (2004).

[23] Ivantsov G. P. , Doklady Akademii Nauk SSSR 58 (1947); 567.

[24] Kurz W., Fisher D.J., Fundamentals of Solidification, Third edition, Trans Tech Publications, Switzerland (1992).

[25] Mosbah S., Bellet M., Gandin Ch.-A. Solidification and Gravity 2008, conference proceedings; in press. Eds. A. Roósz et al. Materials Science Forum, Trans Tech Publications Ltd.

[26] S. McFadden, D. J. Browne, Ch.-A. Gandin. Metallurgical and Materials Transactions A (2009): 40:662. 
[27] Ch.-A. Gandin, J. Blaizot, S. Mosbah, M. Bellet, G. Zimmermann, L. Sturz, D. J. Browne, S. McFadden, H. Jung, B. Billia, N. Mangelinck, H. Nguyen Thi, Y. Fautrelle, X. Wang. Solidification and Gravity 2008, conference proceedings, in press. Eds. A. Roósz et al. Materials Science Forum, Trans Tech Publications Ltd.

[28] Mosbah S., Gandin Ch.-A., Brogly J., Crozier B., Volkmann Th., Herlach D. 5th Decennial International Conference on Solidification Processing, conference proceedings (2007) 80. Ed. H. Jones. The University of Sheffield, U. K.

[29] Sarreal J. A., Abbaschian G. J. Metallurgical Transactions A (1986); 17:2063.

[30] Flemings M. C., Nereo G. E. Trans. AIME (1967) 239:1449.

[31] Lesoult G., Gandin Ch.-A., Niane N.T. Acta Materialia (2003) 51:5263.

[32] Niane N.T., Gandin Ch.-A., Lesoult G. Solidification and Gravity 2004, conference proceedings, Materials Science Forum (2006) 508:175. Eds A. Roósz, M. Rettenmayr, Z. Gácsi. Trans Tech Publications, Switzerland. 


\section{Figure captions}

Figure 1 Schematic view of the model with an illustration of (a) the topological coupling between the tessellation made of the square cells, $v$, defined by their center $\mathrm{C}_{v}$, in the cellular automaton grid and the triangles of the finite element mesh, F, defined by the nodes $n_{i},{ }^{F}(i=[1,3])$ and $(b)$ the simplified spatial representation of the growing dendritic microstructure in a cell $v$ using a square centered in $\mathrm{G}_{v}$ with a half diagonal $\mathrm{R}^{\mathrm{e}}{ }_{v}$ and an orientation $\theta$ with respect to the $\mathrm{x}$-axis. The cells painted in grey are mushy, i.e. made of a mixture of the solid phase and the liquid phase, the fraction of which being provided by a microsegregation model. The primary and secondary dendrite arm spacing, respectively $\lambda_{, 1}$ and $\lambda_{, 2}$, are also shown in (a), together with the size, $R^{f}$, that defines the mushy zone fraction in each cell (proportional to $\mathrm{R}^{\mathrm{e}}{ }_{\mathrm{v}} / \mathrm{R}^{\mathrm{f}}$ ).

Figure 2 2D CAFE model simulation results for the solidification of an atomized Al-10wt $\% \mathrm{Cu}$ droplet. A single nucleation event is assumed at the center of the spherical domain with $30 \mathrm{~K}$ undercooling. Simulation is carried out for a quarter of a disk in axisymmetric coordinates with a radius equal to $125 \mu \mathrm{m}$. Maps are drawn when the volume fraction of the grain is about $0.64[-]$ (calculated as the ratio of the grain volume over the simulation domain volume). The top left shows: (a) the finite element mesh and the CA growth front (black line), (b) the temperature, (c) the average composition, and (d) the volume fraction of solid phase. In addition, the final solute profile predicted by the CAFE model, black line, is compared to the Heringer et al. model prediction, (e).

Figure 3 Present model and the Wang and Beckermann model [9] predictions of the temporal evolution of the mushy zone, $\mathrm{g}^{\mathrm{m}}$, and the volume fraction of the internal solid phase, $\mathrm{g}^{\mathrm{sm}}$ , for three $\mathrm{Al}-4 \mathrm{wt} \% \mathrm{Cu}$ alloy equiaxed grains with a final radius $\mathrm{R}^{\mathrm{f}}=0.1,1$ and $10 \mathrm{~mm}$. In the presented simulations, the initially liquid system exchanges heat by convection with a constant and equal heat transfer coefficient, $\mathrm{h}_{\mathrm{ext}}=27 \mathrm{Wm}^{-2} \mathrm{~K}^{-1}$, with an homogenous external temperature, $T_{\text {ext }}=293 \mathrm{~K}$, through the final grain radius, $R^{f}$. Calculations are achieved for $\lambda_{1}=\lambda_{2}$ when the average composition of the extradendritic liquid phase is used, $\mathrm{w}^{\zeta}=\left\langle\mathrm{w}^{1},{ }_{v}\right\rangle$, and when the average composition of the CA defining the mushy zone front is used, $w^{\zeta}=\left\langle w_{v}\right\rangle$, for the calculation of growth rate. The solidification time, $t_{\mathrm{s}}$, used for normalization are 3, 40 and $300[\mathrm{~s}]$ for respectively $R^{f}=0.1,1$ and $10 \mathrm{~mm}$.

Figure 4 The same as Figure 3 with the analysis of the effect of the primary dendrite arm spacing on the model predictions, green curves, compared to the Wang and Beckermann [9] model, black curves. 
Figure 5 Effect of the primary dendrite arm spacing, $\lambda_{1}$, as well as the calculation approach of the growth rate, effect of $\mathrm{w}^{\dagger}$, on the solute diffusion in the extra-dendritic liquid phase. Present model, green curves, and the Wang and Beckermann [9] model, black curves, prediction of the temporal evolution of the average composition of the extra-dendritic liquid, for three equiaxed grains with a final radius of $0.1,1$ and $10 \mathrm{~mm}$. the equivalent spherical shape of the grain is simulated of an $\mathrm{Al} 4 \mathrm{wt} \% \mathrm{Cu}$ alloy. Grains exchange heat by convection with a constant and equal heat transfer coefficient, $\mathrm{h}=27 \mathrm{~W} \mathrm{~m}^{-2} \mathrm{~K}^{-1}$, with a homogenous external temperature, $T_{\infty}=293 \mathrm{~K}$, through its final radius, $R_{f}$. The effect of the primary dendrite arms spacing is analyzed, comparing line 1 and 2, as well as the calculation of the growth rate, comparing column 1 and 2 . Curves are drawn until the mushy zone reach the boundary limit, i.e. $\mathrm{g}^{\mathrm{m}}=1$. The solidification time, $\mathrm{t}_{\mathrm{s}}$, used for normalization are 3,40 and 300 [s] for respectively $R^{\mathrm{f}}=0.1,1$ and $10 \mathrm{~mm}$.

Figure 6 Measured temperature, thick grey curves, for the Al- 4, 14 and 24wt $\% \mathrm{Cu}$ droplets with triggered nucleation together with the predicted averaged system temperature by the present model, black curves. The predicted temperature at the bottom, $\mathbf{\nabla},-$, and at the top, $\mathbf{\Lambda},-$, of the simulation domain are also drawn. Measurements have been achieved using an optical pyrometer at the top of the system. For the Al-24wtCu, nucleation undercooling for the primary solid phase, $\Delta \mathrm{T}^{\alpha}{ }_{{ }_{\mathrm{N}}}=32 \mathrm{~K}$, as well as for the eutectic structure, $\Delta \mathrm{T}^{\mathrm{E}}{ }_{\mathrm{N}}=20 \mathrm{~K}$, have been measured. No undercooling is considered for the Al4 and $14 \mathrm{wt} \% \mathrm{Cu}$ droplets. Isothermal eutectic transformation is assumed at the measured nucleation temperature for all samples.

Figure 7 Characterization of a central meridian cross section of aluminum-copper samples processed by electromagnetic levitation with triggered nucleation for alloys with (c1) 4 , (c2) 14, and (c3) $24 \mathrm{wt} \% \mathrm{Cu}$. Distributions are presented for (11) the normalized average copper content, $\left(\langle\mathrm{w}\rangle-\mathrm{w}_{0}\right) / \mathrm{w}_{0}[-],(12)$ the normalized average eutectic fraction, $\left(\left\langle\mathrm{g},{ }^{\mathrm{E}}\right\rangle-\mathrm{g}_{\mathrm{GS}},{ }^{\mathrm{E}}\right) / \mathrm{g}_{\mathrm{GS}},{ }^{\mathrm{E}}[-]$ and (13) the dendrite arm spacing, $\langle\mathrm{DAS}\rangle[\mu \mathrm{m}]$.

Figure 8 Prediction of the present model for the $\mathrm{Al}-\mathrm{Cu}$ samples processed by electromagnetic levitation. Maps present, (1) the distribution of the normalized average copper content, $\left(\langle\mathrm{w}\rangle-\mathrm{w}_{0}\right) / \mathrm{w}_{0}[-]$, and (2) the eutectic volume fraction, $\left(\mathrm{g},{ }^{\mathrm{E}}-\mathrm{g}_{\mathrm{GS}}{ }^{\mathrm{E}}\right) / \mathrm{g}_{\mathrm{GS}}{ }^{\mathrm{E}}[-]$ when solidification is completed. $\mathrm{g}_{\mathrm{GS}}$, , is the volume fraction of the eutectic phase predicted by the Gulliver - Scheil model for the nominal composition, $\mathrm{w}_{0}$, given in Table 2. Thick black curvature indicates the contact area of the alumina plate at the bottom of the droplet surface simulated with the model as a constant surface, A1. Heat is also extracted through the droplet free surface, thick grey line, A2, as explained in the Prediction section. 


\section{Table captions}

Table 1 Mathematical expressions used for the diffusion lengths, $\mathrm{I}_{{ }_{\mathrm{v}}}^{\mathrm{sd}}$ and $\mathrm{l}^{\mathrm{ld}}{ }_{\mathrm{v}}$, and the interfacial area concentrations, $S^{\text {sd }}{ }_{v}$ and $S^{\text {ld }}{ }_{v}$, entering Equations 3, 4 and 5.

Table 2 Summary of the simulation data and parameters.

Table 3 Summary of the measurements deduced from the recorded cooling curves for six Al-Cu samples processed by electromagnetic levitation. Each alloy composition being identified by its nominal copper content, $\mathrm{w}_{0}$, spontaneous and triggered nucleation were used. Measurements consist of the cooling rates prior to solidification, $\mathrm{T}^{\circ},\left(\mathrm{t}^{\mathrm{a}} \mathrm{t}_{\mathrm{N}},{ }^{\mathrm{s}}\right)$, and after completion of solidification, $\mathrm{T},\left(\mathrm{t}>\mathrm{t}_{\text {end }}\right)$, the nucleation undercooling of the dendritic structure, $\Delta \mathrm{T}_{\mathrm{N}}$,, , the nucleation undercooling of the eutectic structure, $\Delta \mathrm{T}_{\mathrm{N}}, \mathrm{E}$, the solidification time measured from the nucleation of the dendritic structures, $\mathrm{t}_{\mathrm{N}}$, , , up to the completion of solidification, $\mathrm{t}_{\text {end }}$.

Table 4 Summary of the measurements for the average over the sample sections of the $\mathrm{Cu}$ composition, $\mathrm{w}_{\mathrm{D}}$, the dendrite arm spacing, $\mathrm{DAS}_{\mathrm{D}}$, and the volume fraction of eutectic, $g_{D},{ }^{E}$, compared with the predictions using the present CAFE model, $\mathrm{g}_{\mathrm{CAFE}}{ }^{\mathrm{E}}$, a semi-analytical model, $\mathrm{g}_{[4]},{ }^{\mathrm{E}}[4]$, as well as the Gulliver-Scheil prediction, $\mathrm{g}_{\mathrm{GS}},{ }^{\mathrm{E}}$. 


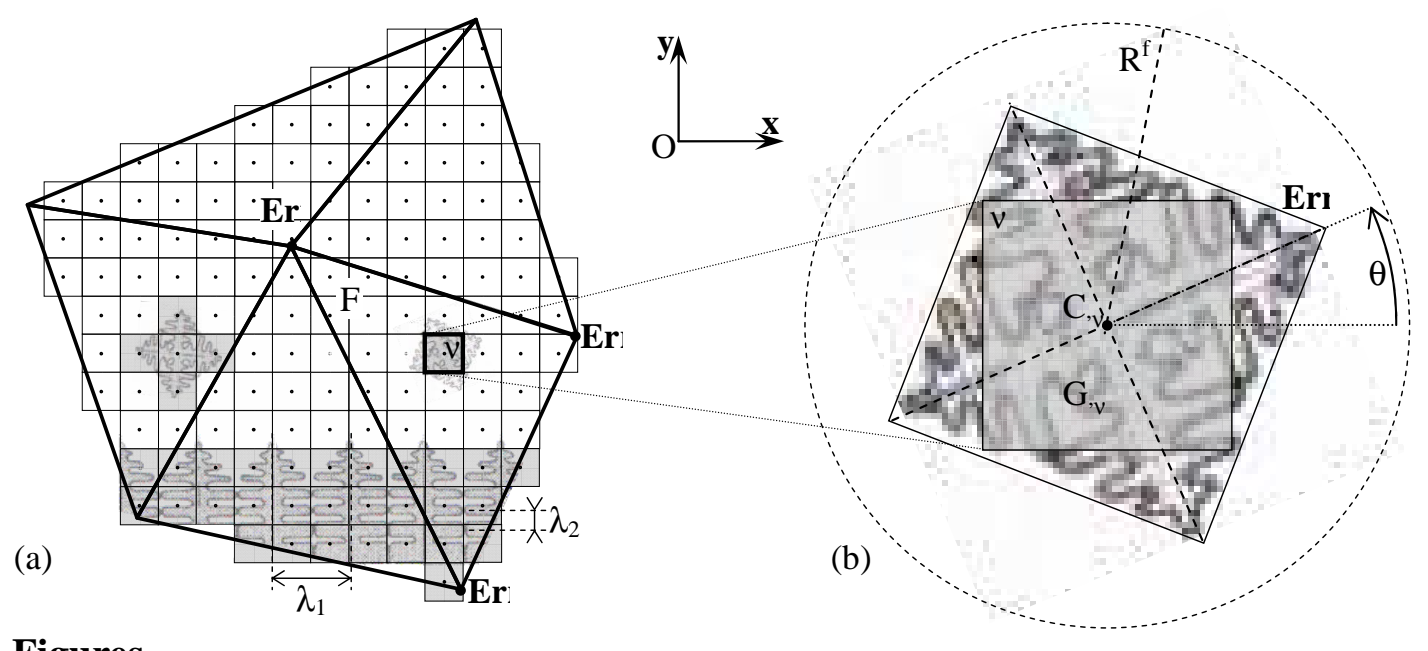

Figures

Figure 1. Schematic view of the model with an illustration of (a) the topological coupling between the tessellation made of the square cells, $v$, defined by their center $\mathrm{C}_{v}$, in the cellular automaton grid and the triangles of the finite element mesh, F, defined by the nodes $n_{i}, F(i=[1,3])$ and (b) the simplified spatial representation of the growing dendritic microstructure in a cell $v$ using a square centered in $\mathrm{G}_{, v}$ with a half diagonal $\mathbf{R}^{\mathrm{e}}{ }_{v}$ and an orientation $\theta$ with respect to the $x$-axis. The cells painted in grey are mushy, i.e. made of a mixture of the solid phase and the liquid phase, the fraction of which being provided by a microsegregation model. The primary and secondary dendrite arm spacing, respectively $\lambda_{, 1}$ and $\lambda_{, 2}$, are also shown in (a), together with the size, $R^{\mathrm{f}}$, that defines the mushy zone fraction in each cell (proportional to $\mathrm{R}^{\mathrm{e}}{ }_{\mathrm{v}} / \mathrm{R}^{\mathrm{f}}$ ). 

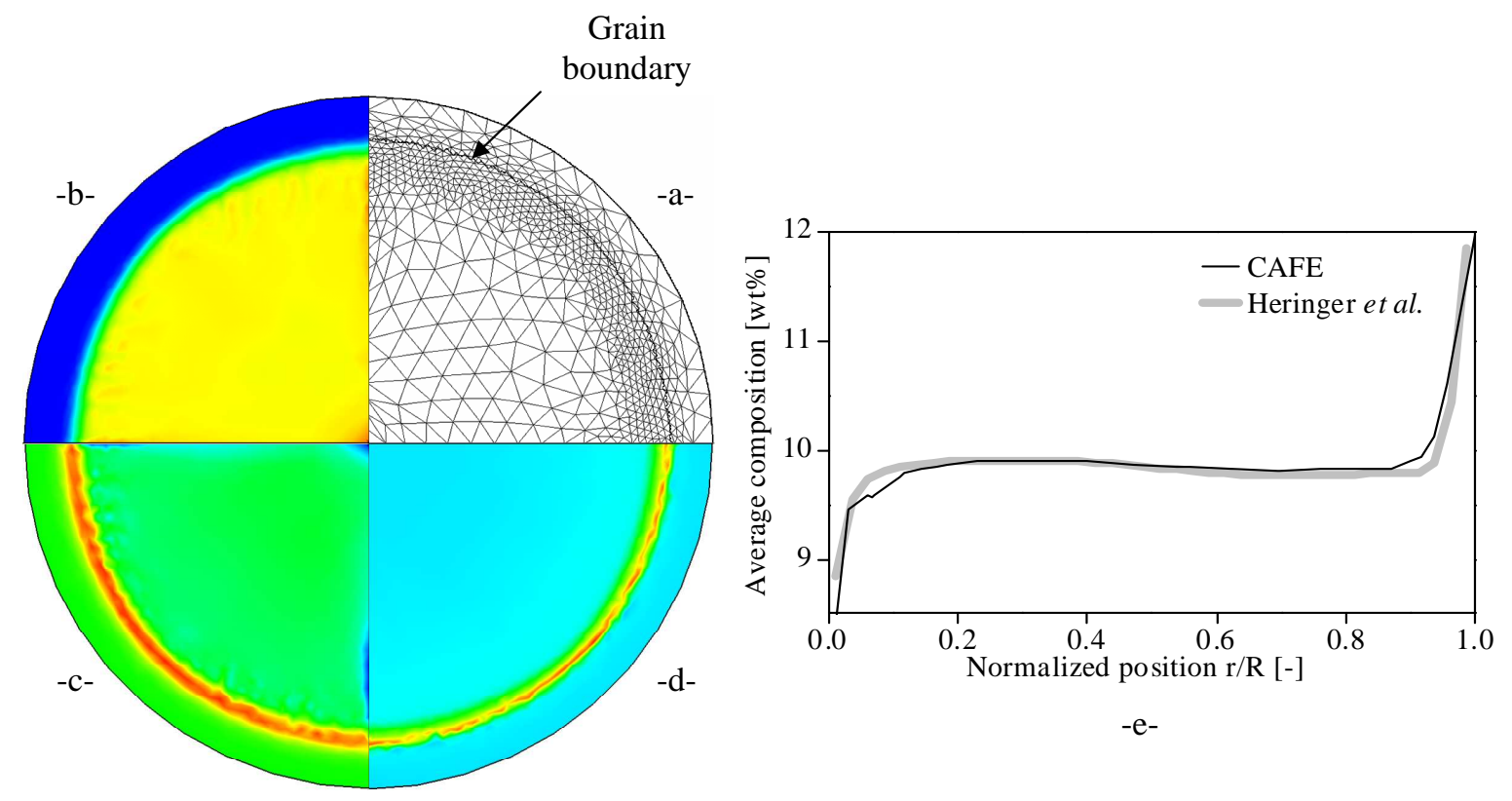

$\begin{array}{ccccccc} & & & & & \mathrm{a} & \text { FE mesh + Grain boundary } \\ 0 & 0.1 & 0.2 & 0.3 & 0.4 & \mathrm{~b} & \text { solid fraction [-] } \\ 9 & 9.5 & 10 & 10.5 & 11 & \mathrm{c} & \text { Average composition [wt\%] } \\ 889 & 889.87 & 890.25 & 890.62 & 891 & \mathrm{~d} & \text { Temperature [K] }\end{array}$

Figure 2. 2D CAFE model simulation results for the solidification of an atomized $\mathrm{Al}-10 \mathrm{wt} \% \mathrm{Cu}$ droplet. A single nucleation event is assumed at the center of the spherical domain with $30 \mathrm{~K}$ undercooling. Simulation is carried out for a quarter of a disk in axisymmetric coordinates with a radius equal to $125 \mu \mathrm{m}$. Maps are drawn when the volume fraction of the grain is about 0.64 [-] (calculated as the ratio of the grain volume over the simulation domain volume). The top left shows: (a) the finite element mesh and the CA growth front (black line), (b) the temperature, (c) the average composition, and (d) the volume fraction of solid phase. In addition, the final solute profile predicted by the CAFE model, black line, is compared to the Heringer et al. model prediction, (e). 

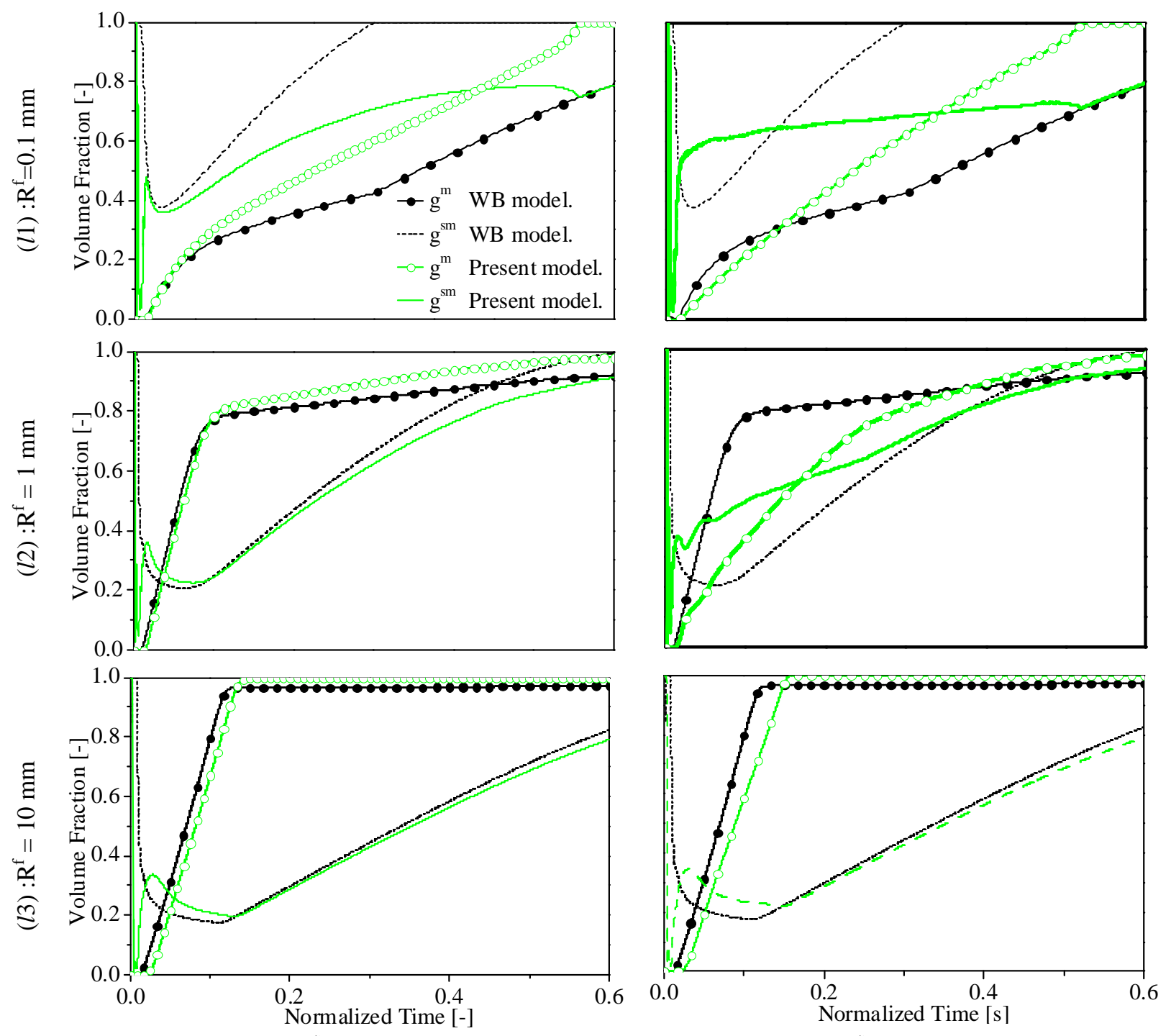

(c1) : $w^{\zeta}=\left\langle w^{1},\right\rangle^{1}, \lambda_{1}=\lambda_{2}$

(c2) : $w^{\zeta}=\langle w\rangle_{n}, \lambda_{1}=\lambda_{2}$

Figure 3: Present model and the Wang and Beckermann model [9] predictions of the temporal evolution of the mushy zone, $\mathrm{g}^{\mathrm{m}}$, and the volume fraction of the internal solid phase, $\mathrm{g}^{\mathrm{sm}}$ , for three $\mathrm{Al}-4 \mathrm{wt} \% \mathrm{Cu}$ alloy equiaxed grains with a final radius $\mathrm{R}^{\mathrm{f}}=0.1,1$ and $10 \mathrm{~mm}$. In the presented simulations, the initially liquid system exchanges heat by convection with a constant and equal heat transfer coefficient, $\mathrm{h}_{\mathrm{ext}}=27 \mathrm{Wm}^{-2} \mathrm{~K}^{-1}$, with an homogenous external temperature, $T_{\text {ext }}=293 \mathrm{~K}$, through the final grain radius, $\mathrm{R}^{\mathrm{f}}$. Calculations are achieved for $\lambda_{1}=\lambda_{2}$ when the average composition of the extradendritic liquid phase is used, $w^{\zeta}=\left\langle w^{1}{ }_{v}\right\rangle^{1}$, and when the average composition of the CA defining the mushy zone front is used, $w^{\zeta}=\left\langle w_{v}\right\rangle$, for the calculation of growth rate. The solidification time, $t_{s}$, used for normalization are 3,40 and 300 [s] for respectively $R^{f}=0.1,1$ and $10 \mathrm{~mm}$. 

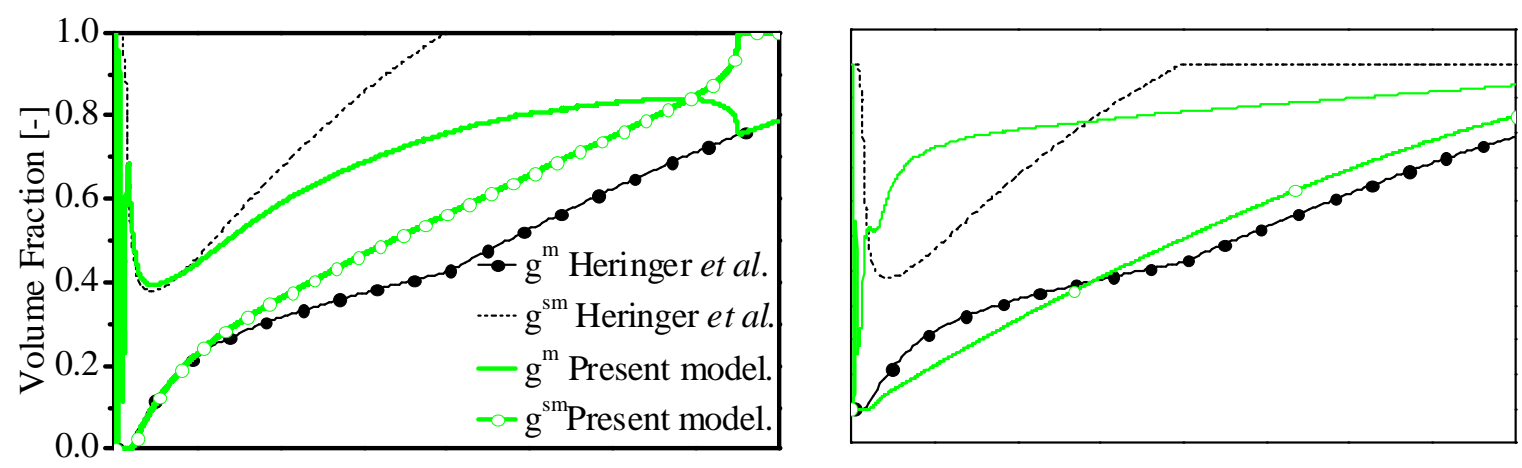

ఏ
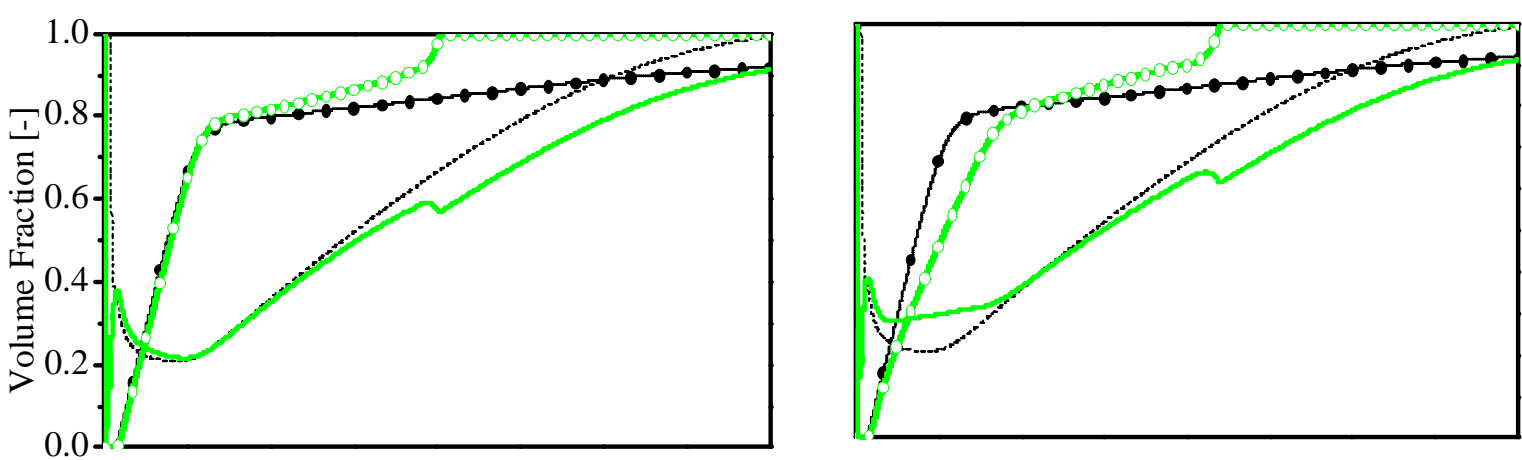

$\frac{\Xi}{\beth}$
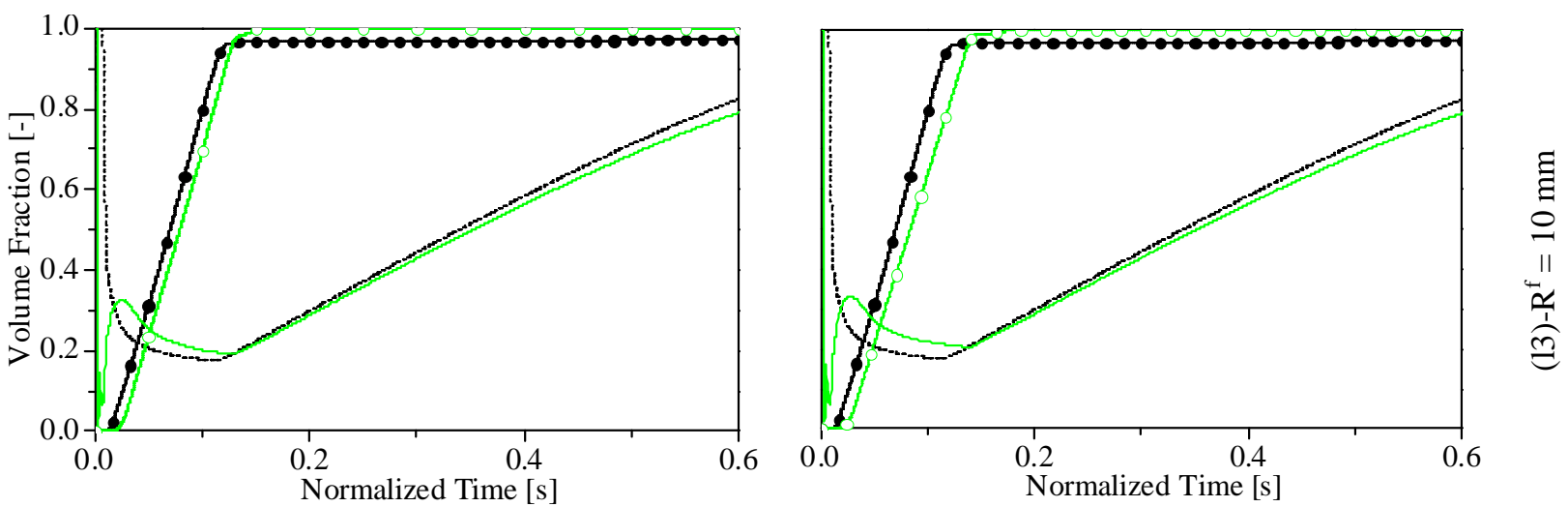

(c1) $-w^{\zeta}=\left\langle w^{1},>^{1}, \lambda_{1}=4 \lambda_{2}\right.$

$(\mathrm{c} 2)-\mathrm{w}^{\zeta}=\left\langle\mathrm{w}_{\mathrm{n}}\right\rangle, \lambda_{1}=4 \lambda_{2}$

Figure 4: The same as Figure 3 with the analysis of the effect of the primary dendrite arm spacing on the model predictions, green curves, compared to the Wang and Beckermann [9] model, black curves. 

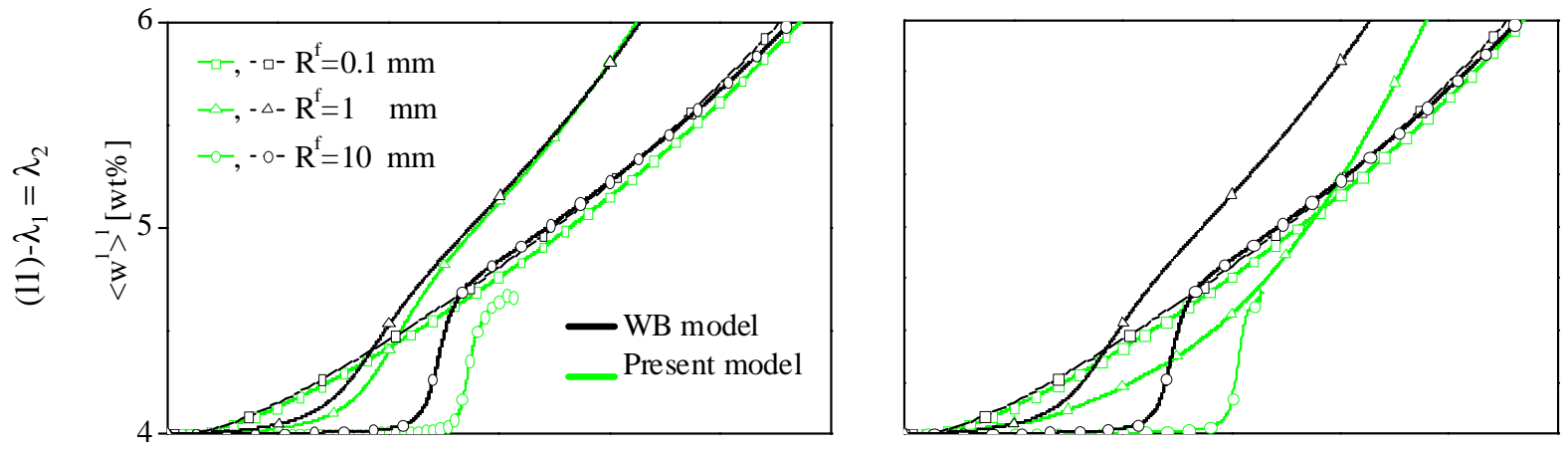

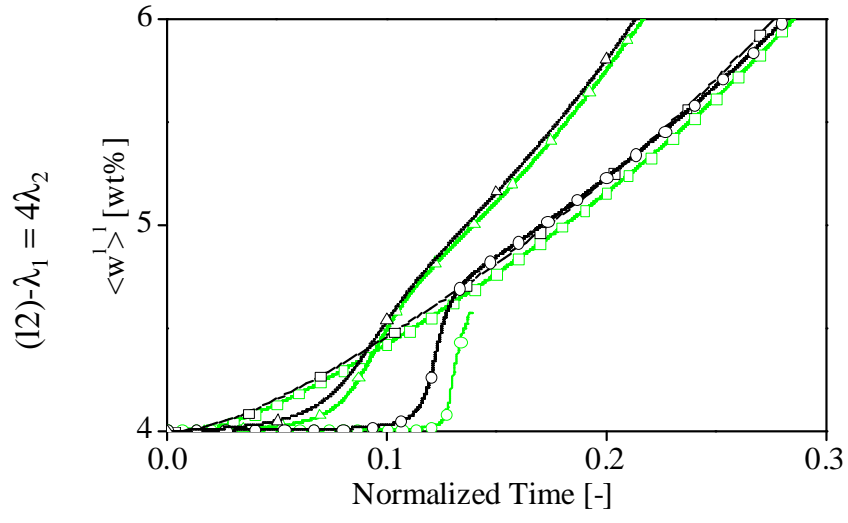

$(\mathrm{c} 1)-\mathrm{w}^{\dagger}=\left\langle\mathrm{w}^{1}\right\rangle^{1}$

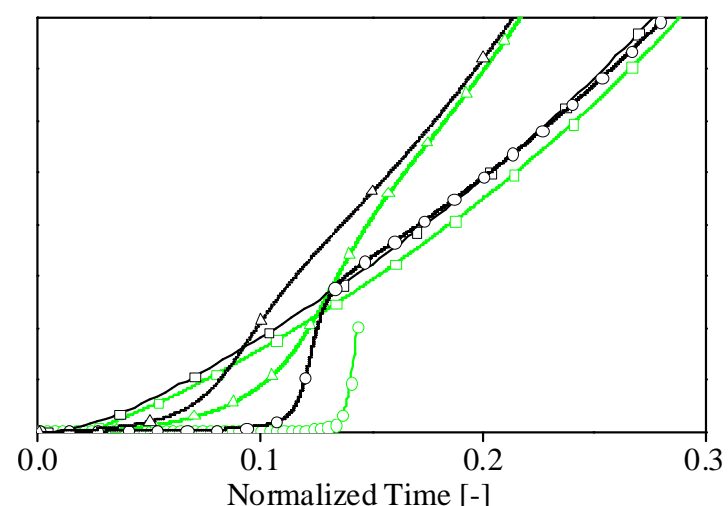

(c2) $-\mathrm{w}^{\dagger}=\left\langle\mathrm{w}_{\mathrm{v}}\right\rangle$

Figure 5: Effect of the primary dendrite arm spacing, $\lambda_{1}$, as well as the calculation approach of the growth rate, effect of $\mathrm{w}^{\dagger}$, on the solute diffusion in the extra-dendritic liquid phase. Present model, green curves, and the Wang and Beckermann [9] model, black curves, prediction of the temporal evolution of the average composition of the extra-dendritic liquid, for three equiaxed grains with a final radius of $0.1,1$ and $10 \mathrm{~mm}$. the equivalent spherical shape of the grain is simulated of an $\mathrm{Al} 4 \mathrm{wt} \% \mathrm{Cu}$ alloy. Grains exchange heat by convection with a constant and equal heat transfer coefficient, $\mathrm{h}=27 \mathrm{~W} \mathrm{~m} \mathrm{~K}^{-1}$, with a homogenous external temperature, $T_{\infty}=293 \mathrm{~K}$, through its final radius, $R_{\mathrm{f}}$. The effect of the primary dendrite arms spacing is analyzed, comparing line 1 and 2, as well as the calculation of the growth rate, comparing column 1 and 2. Curves are drawn until the mushy zone reach the boundary limit, i.e. $\mathrm{g}^{\mathrm{m}}=1$. The solidification time, $\mathrm{t}_{\mathrm{s}}$, used for normalization are 3, 40 and 300 [s] for respectively $\mathrm{R}^{\mathrm{f}}=0.1,1$ and $10 \mathrm{~mm}$. 

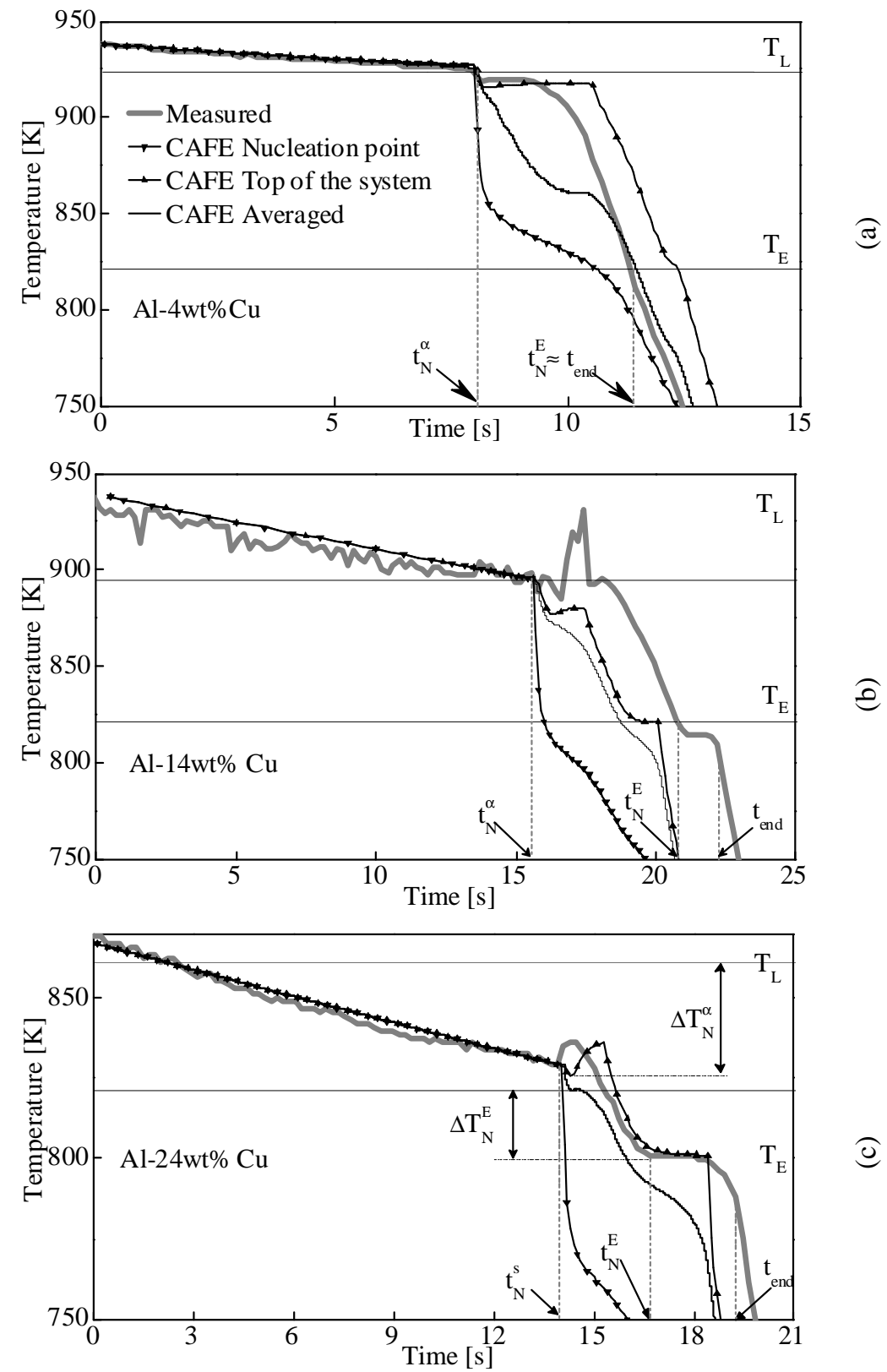

Figure 6: Measured temperature, thick grey curves, for the Al- 4, 14 and 24wt $\% \mathrm{Cu}$ droplets with triggered nucleation together with the predicted averaged system temperature by the present model, black curves. The predicted temperature at the bottom, $\mathbf{v},-$, and at the top, $\mathbf{\Lambda},-$, of the simulation domain are also drawn. Measurements have been achieved using an optical pyrometer at the top of the system. For the $\mathrm{Al}-24 \mathrm{wtCu}$, nucleation undercooling for the primary solid phase, $\Delta \mathrm{T}^{\alpha}{ }_{\mathrm{N}}=32 \mathrm{~K}$, as well as for the eutectic structure, $\Delta \mathrm{T}^{\mathrm{E}}{ }_{\mathrm{N}}=20 \mathrm{~K}$, have been measured. No undercooling is considered for the Al- 
4 and $14 \mathrm{wt} \% \mathrm{Cu}$ droplets. Isothermal eutectic transformation is assumed at the measured nucleation temperature for all samples. 


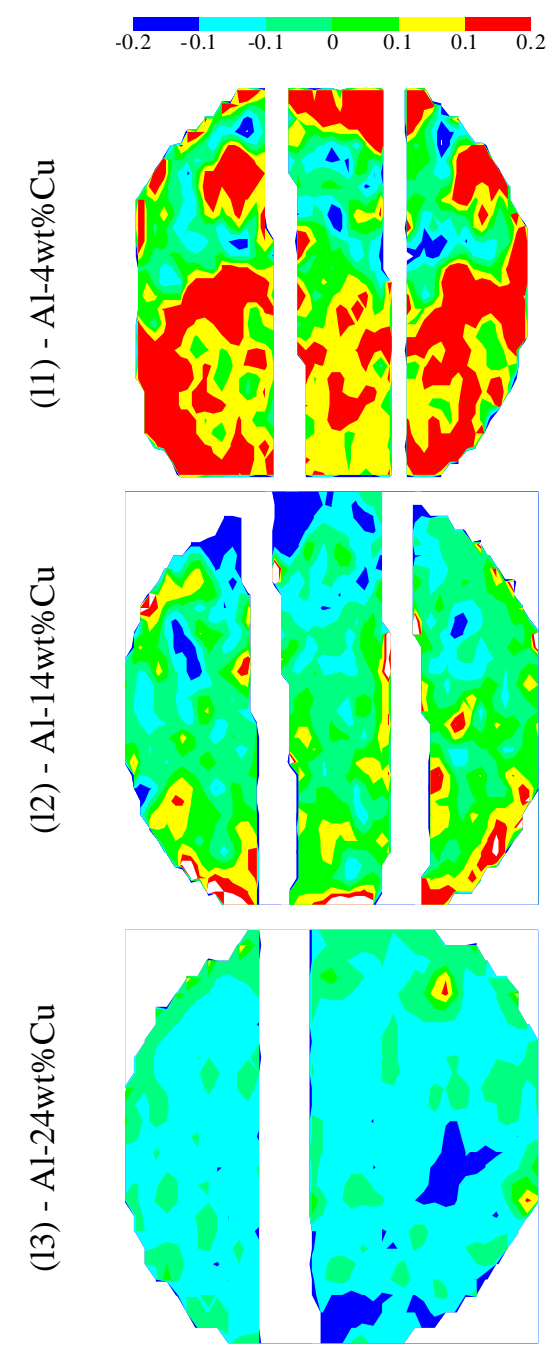

(c1) $\left(<\mathrm{w}>-\mathrm{w}_{0}\right) / \mathrm{w}_{0}{ }^{(1)}$
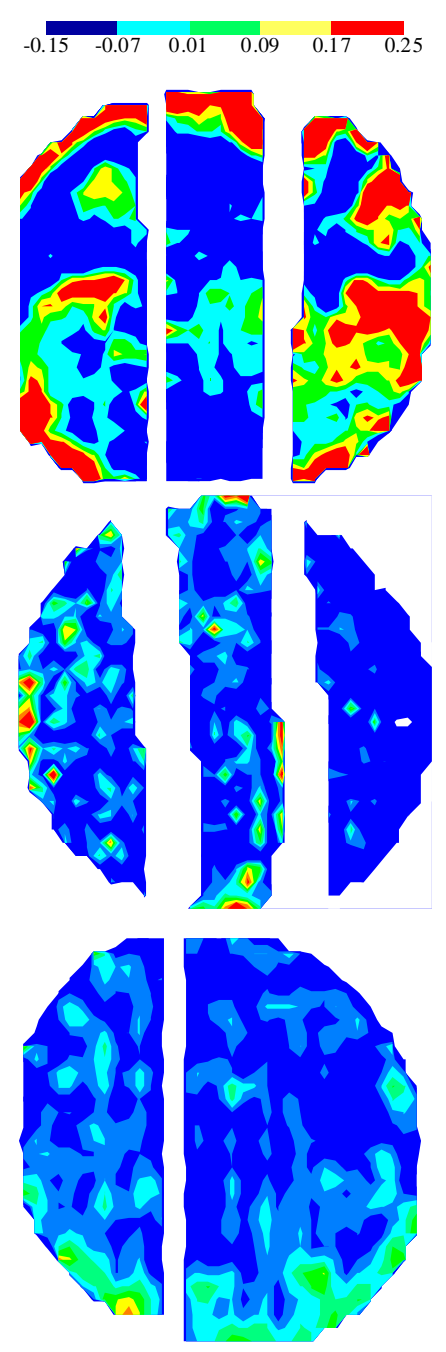

(c2) $\left(<\mathrm{g},{ }^{\mathrm{E}}>-\mathrm{g}_{\mathrm{GS}},{ }^{\mathrm{E}}\right) / \mathrm{g}_{\mathrm{GS}} \mathrm{E}(2)$
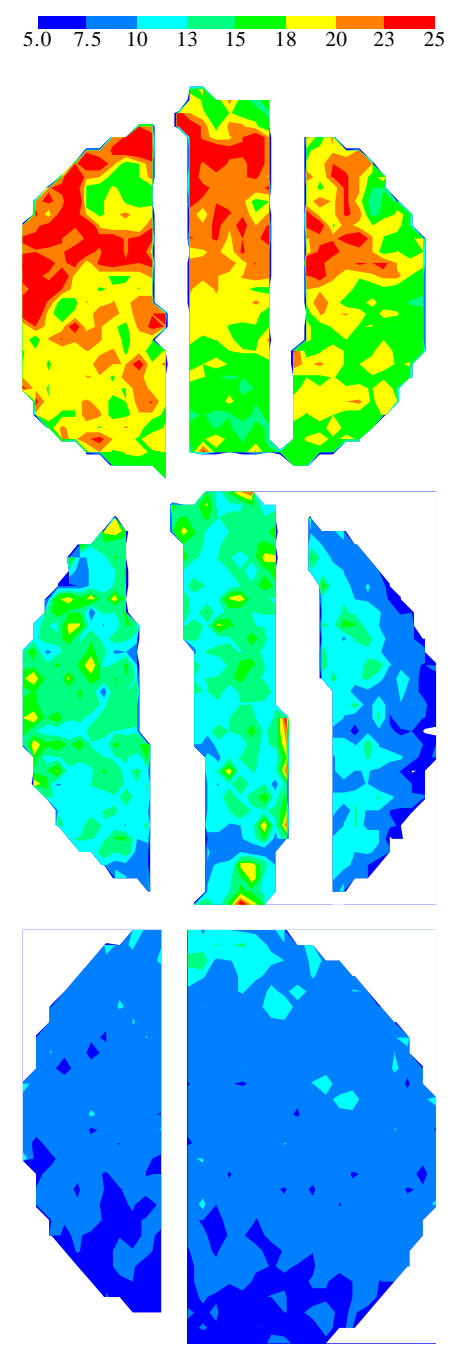

(c3) $\langle$ DAS $>$ (2)

(1) Measurements of the copper content, $\langle\mathrm{w}\rangle$, are averaged over $120 \cdot 10^{-6} \mathrm{~m} \times 150 \cdot 10^{-6} \mathrm{~m}$ surface areas.

(2) Measurements of the volume fraction of the eutectic structure, $\mathrm{g}$, , are averaged over $150 \cdot 10^{-6} \mathrm{~m} \times 150 \cdot 10^{-6} \mathrm{~m}$ surface areas.

Figure 7: Characterization of a central meridian cross section of aluminum-copper samples processed by electromagnetic levitation with triggered nucleation for alloys with (c1) 4 , (c2) 14, and (c3) $24 \mathrm{wt} \% \mathrm{Cu}$. Distributions are presented for (11) the normalized average copper content, $\left(\langle\mathrm{w}\rangle-\mathrm{w}_{0}\right) / \mathrm{w}_{0}[-]$, (12) the normalized average eutectic fraction, $\left(<\mathrm{g},{ }^{\mathrm{E}}>-\mathrm{g}_{\mathrm{GS}}{ }^{\mathrm{E}}\right) / \mathrm{g}_{\mathrm{GS}}{ }^{\mathrm{E}}[-]$ and $(13)$ the dendrite arm spacing, $\langle\mathrm{DAS}\rangle[\mu \mathrm{m}]$. 

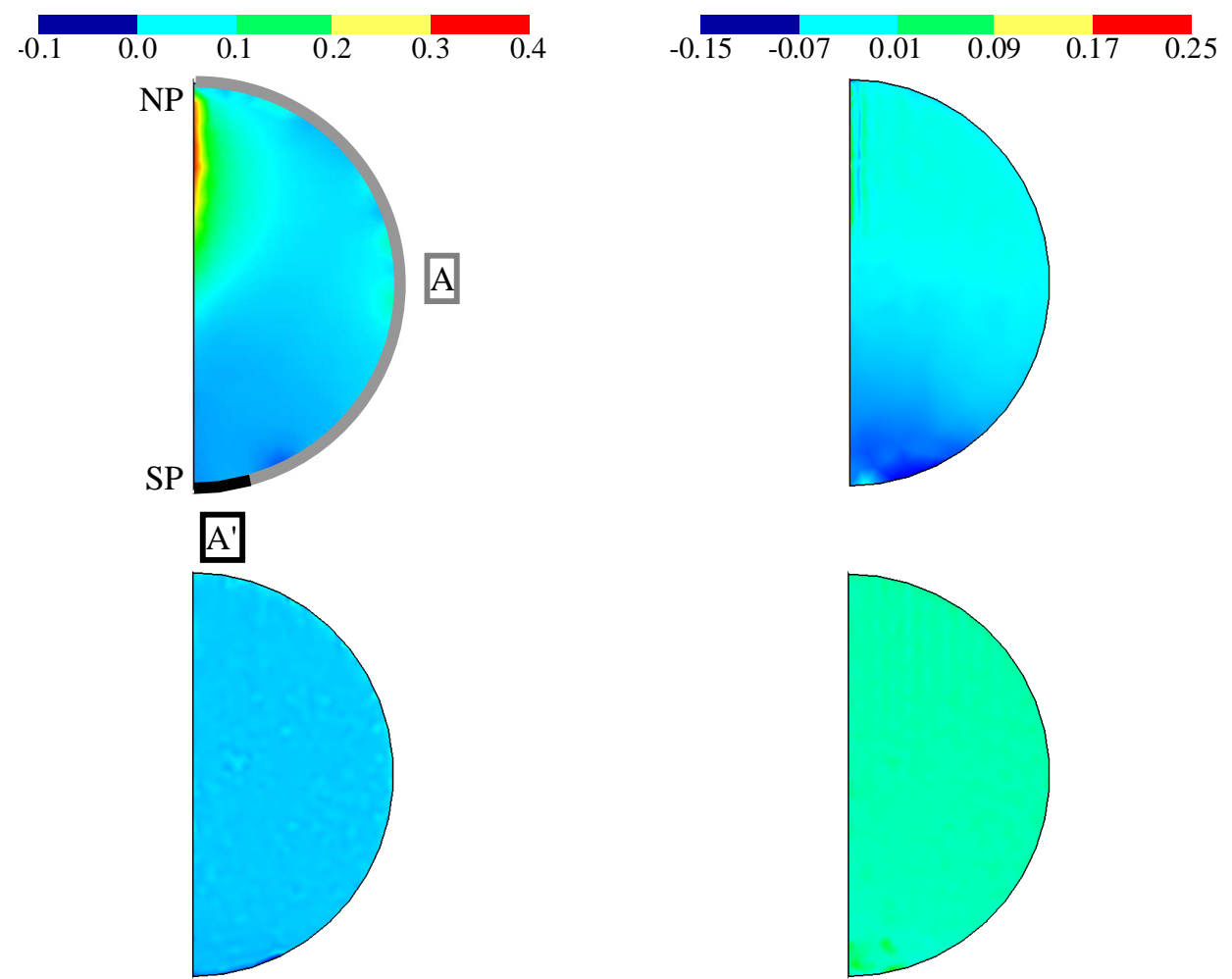

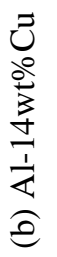
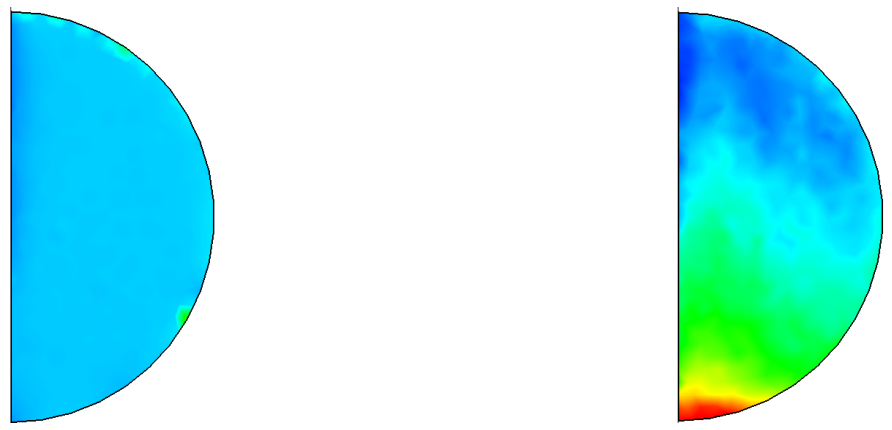

\begin{tabular}{l}
0 \\
0 \\
0 \\
3 \\
3 \\
\multirow{2}{4}{} \\
$\frac{1}{2}$ \\
1 \\
0
\end{tabular}

(1) $-\left(<w>-w_{0}\right) / w_{0}[-]$

(2) $-\left(\mathrm{g},{ }^{\mathrm{E}}-\mathrm{g}_{\mathrm{GS}},{ }^{\mathrm{E}}\right) / \mathrm{g}_{\mathrm{GS}},{ }^{\mathrm{E}}[-]$

Figure 8: Prediction of the present model for the Al-Cu samples processed by electromagnetic levitation. Maps present, (1) the distribution of the normalized average copper content, $\left(<\mathrm{w}>-\mathrm{w}_{0}\right) / \mathrm{w}_{0}[-]$, and (2) the eutectic volume fraction, $\left(\mathrm{g},{ }^{\mathrm{E}}-\mathrm{g}_{\mathrm{GS}},{ }^{\mathrm{E}}\right) / \mathrm{g}_{\mathrm{GS}},{ }^{\mathrm{E}}[-]$ when solidification is completed. $\mathrm{g}_{\mathrm{GS}}$, is the volume fraction of the eutectic phase predicted by the Gulliver - Scheil model for the nominal composition, $\mathrm{w}_{0}$, given in Table 2 . Thick black curvature indicates the contact area of the alumina plate at the bottom of the droplet surface simulated with the model as a constant surface, A1. Heat is also extracted through the droplet free surface, thick grey line, A2, as explained in the Prediction section. 
Tables

\begin{tabular}{|c|c|c|}
\hline Interface $\alpha \beta$ & Diffusion length $1^{\alpha \beta}{ }_{, v}$ & \\
\hline sd & Erreur $!$ & \\
\hline ld & Erreur ! Erreur $!$ & \\
\hline
\end{tabular}

Table 1. Mathematical expressions used for the diffusion lengths, $\mathrm{l}^{\mathrm{sd}}{ }_{\mathrm{v}}$ and $\mathrm{l}^{\mathrm{ld}}{ }_{\mathrm{v}}$, and the interfacial area $\mathrm{c}$

Equations 3, 4 and 5. 


\begin{tabular}{|c|c|c|c|c|c|c|c|}
\hline \multirow{2}{*}{\begin{tabular}{|l} 
Property \\
Nominal composition
\end{tabular}} & \multirow{2}{*}{\begin{tabular}{|l} 
Symbol \\
$\mathrm{w}_{0}$
\end{tabular}} & \multirow{2}{*}{\begin{tabular}{|l} 
Unit \\
[wt\%]
\end{tabular}} & \multirow{2}{*}{$\begin{array}{l}\text { Figure 2 } \\
{[2]} \\
10 .\end{array}$} & \begin{tabular}{|l|} 
Figures 3-5 \\
{$[10]$}
\end{tabular} & \multicolumn{3}{|c|}{$\begin{array}{l}\text { Figures 6-8 } \\
\text { Table } 4 \text { [4] }\end{array}$} \\
\hline & & & & 4. & 4. & 14. & 24. \\
\hline Liquidus temperature & $\mathrm{T}_{\mathrm{L}}$ & {$[\mathrm{K}]$} & 899.9 & 923. & 923. & 895. & 861. \\
\hline Segregation coefficient & $\mathrm{k}$ & {$[-]$} & $\$$ & $\$$ & 0.17 & & \\
\hline Eutectic composition & $w_{E}$ & [wt $\%]$ & 34.38 & 33.2 & 33.2 & & \\
\hline Liquidus slope & $\mathrm{m}_{\mathrm{L}}$ & {$\left[\mathrm{wt} \% \mathrm{~K}^{-1}\right]$} & -3.37 & -3.49 & $\$$ & & \\
\hline Eutectic temperature & $\mathrm{T}_{\mathrm{E}}$ & {$[\mathrm{K}]$} & 817.74 & 821. & 821. & & \\
\hline Gibbs-Thomson coefficient & $\Gamma$ & {$[\mathrm{K} \mathrm{m}]$} & $\$$ & $\$$ & $\$$ & & \\
\hline Heat capacity & $\mathrm{C}_{\mathrm{p}}$ & {$\left[\mathrm{J} \mathrm{m}^{-3} \mathrm{~K}^{-1}\right]$} & $3 \cdot 10^{6}$ & $3 \cdot 10^{6}$ & $3 \cdot 10$ & & \\
\hline Enthalpy of fusion & $\mathrm{L}$ & {$\left[\mathrm{J} \mathrm{m}^{-3}\right]$} & $9.5 \cdot 10^{8}$ & $10^{9}$ & $10^{9}$ & & \\
\hline Diffusion of $\mathrm{Cu}$ in liquid $\mathrm{Al}$ & $D^{1}$ & {$\left[\mathrm{~m}^{2} \mathrm{~s}^{-1}\right]$} & $4.37 \cdot 10^{-9}$ & $4.37 \cdot 10^{-9}$ & 4.37 . & $\cdot 10^{-9}$ & \\
\hline Diffusion of $\mathrm{Cu}$ in solid $\mathrm{Al}$ & $D^{s}$ & {$\left[\mathrm{~m}^{2} \mathrm{~s}^{-1}\right]$} & 0 . & 0. & $5 \cdot 10^{-1}$ & & \\
\hline Cell size & & {$[\mathrm{m}]$} & $10 \cdot 10^{-6}$ & $10 \cdot 10^{-6}$ & $10 \cdot 1$ & & \\
\hline Imposed minimum FE mesh size & & {$[\mathrm{m}]$} & $30 \cdot 10^{-6}$ & $30 \cdot 10^{-6}$ & $30 \cdot 1$ & & \\
\hline Imposed maximum FE mesh size & & {$[\mathrm{m}]$} & $200 \cdot 10^{-6}$ & $200 \cdot 10^{-6}$ & 200 . & $10^{-6}$ & \\
\hline Objective relative error on $\langle\mathrm{w}\rangle$ & & {$[-]$} & $10^{-4}$ & $10^{-4}$ & $10^{-4}$ & & \\
\hline Primary dendrite arm spacing & $\lambda_{1}$ & {$[\mathrm{~m}]$} & $\$$ & $\$$ & $\$ \$ \cdot 1$ & & \\
\hline Secondary dendrite arm spacing & $\lambda_{2}$ or DAS & {$[\mathrm{m}]$} & - & - & Table & & \\
\hline Primary nucleation undercooling & $\Delta \mathrm{T}_{\mathrm{N}}^{\mathrm{s}} \mathrm{s}$ & {$[\mathrm{K}]$} & 30. & 0. & Table & & \\
\hline Nucleation undercooling of eutectic & $\Delta \mathrm{T}_{\mathrm{N}}^{\mathrm{E}}$ & {$[\mathrm{K}]$} & 0. & 0. & Table & & \\
\hline Location of nucleation event & & & Center & Center & South & h pole & \\
\hline Domain radius & $\mathrm{R}$ & {$[\mathrm{m}]$} & $125 \cdot 10^{-3}$ & $10^{-4}, 10^{-3}, 10^{-2}$ & 2.65 . & $\cdot 10^{-3}$ & \\
\hline Exchange surface & $A^{\prime}$ & {$\left[\mathrm{m}^{2}\right]$} & 0. & 0. & $4.5 \cdot 1$ & $10^{-6}$ & \\
\hline Exchange surface & $A=4 \pi R^{2}-A^{\prime}$ & {$\left[\mathrm{m}^{2}\right]$} & $\$$ & $\$, \$, \$$ & 83.7 & $\cdot 10^{-6}$ & \\
\hline External temperature & $\mathrm{T}_{\mathrm{ext}}$ & {$[\mathrm{K}]$} & 373. & 293.15 & 293. & & \\
\hline $\begin{array}{l}\text { Initial temperature } \\
\text { (spontaneous nucleation) }\end{array}$ & & {$[\mathrm{K}]$} & $\$$ & $\$$ & $\$$ & $\$$ & $\$$ \\
\hline (triggered nucleation) & & & & & 938. & 938. & 867. \\
\hline $\begin{array}{l}\text { Heat transfer coefficient } \\
\text { (spontaneous nucleation) }\end{array}$ & $\mathrm{h}^{\mathrm{A}}{ }_{\text {ext }}$ & {$\left[\mathrm{W} \mathrm{m} \mathrm{K}^{-2} \mathrm{~K}^{-1}\right]$} & 490. & 27. & $\$$ & $\$$ & $\$$ \\
\hline (triggered nucleation) & & & & & 6.4 & 12. & 13. \\
\hline Heat transfer coefficient & 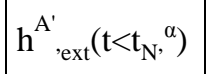 & {$\left[\mathrm{W} \mathrm{m} \mathrm{m}^{-2} \mathrm{~K}^{-1}\right]$} & - & - & 6.4 & 12. & 13. \\
\hline Heat transfer coefficient & $\left(\mathrm{t}>\mathrm{t}_{\mathrm{N}},{ }^{\alpha}\right)$ & & - & - & $10^{4}$ & & \\
\hline
\end{tabular}

Table 2. Summary of the simulation data and parameters. 


\begin{tabular}{|c|c|c|c|c|c|c|}
\hline $\mathrm{w}_{0}[\mathrm{wt} \%]$ & Nucleation & $\Delta \mathrm{T}_{\mathrm{N}},{ }^{\mathrm{s}}\left[{ }^{\circ} \mathrm{C}\right]$ & $\Delta \mathrm{T}_{\mathrm{N}},{ }^{\mathrm{E}}\left[{ }^{\circ} \mathrm{C}\right]$ & $\begin{array}{c}\text { Solidification } \\
\text { time }[\mathrm{s}]\end{array}$ & $\mathrm{T},\left(\mathrm{t}<\mathrm{t}_{\mathrm{N}},{ }^{\mathrm{s}}\right)$ & $\mathrm{T},\left(\mathrm{t}>\mathrm{t}_{\text {end }},\right)$ \\
\hline \multirow{2}{*}{4} & Triggered & 0. & 0. & 3.2 & -1.5 & -64. \\
\hline & Spontaneous & 35. & 20. & 41.5 & -6.6 & - \\
\hline \multirow{2}{*}{14} & Triggered & 0. & 0. & 5.1 & -3.24 & -74. \\
\hline & Spontaneous & 15. & 20. & 63.7 & -6.9 & - \\
\hline \multirow{2}{*}{24} & Triggered & 32. & 20. & 3.0 & -3.51 & -71. \\
\hline & Spontaneous & 25. & 45. & 88.2 & -4.5 & - \\
\hline
\end{tabular}

Table 3. Summary of the measurements deduced from the recorded cooling curves for six $\mathrm{Al}-\mathrm{Cu}$ samples processed by electromagnetic levitation. Each alloy composition being identified by its nominal copper content, $\mathrm{w}_{0}$, spontaneous and triggered nucleation were used. Measurements consist of the cooling rates prior to solidification, $\mathrm{T}^{\cdot},\left(\mathrm{t}<\mathrm{t}_{\mathrm{N}}{ }^{\mathrm{s}}\right)$, and after completion of solidification, $\mathrm{T},\left(\mathrm{t}>\mathrm{t}_{\mathrm{end}}\right)$, the nucleation undercooling of the dendritic structure, $\Delta \mathrm{T}_{\mathrm{N}}$,, , the nucleation undercooling of the eutectic structure, $\Delta \mathrm{T}_{\mathrm{N}}, \mathrm{E}$, the solidification time measured from the nucleation of the dendritic structures, $\mathrm{t}_{\mathrm{N}}, \mathrm{s}$, up to the completion of solidification, $\mathrm{t}_{\text {end }}$. 


\begin{tabular}{|c|c|c|c|c|c|c|c|}
\hline $\begin{array}{c}\mathrm{w}_{0} \\
{[\mathrm{wt} \%]}\end{array}$ & $\begin{array}{c}\mathrm{g}_{\mathrm{GS}}{ }^{\mathrm{E}}{ }^{\mathrm{e}}(1) \\
{[\%]}\end{array}$ & Nucleation & $\begin{array}{c}\mathrm{w}_{\mathrm{D}} \\
{[\mathrm{wt} \%]}\end{array}$ & $\begin{array}{r}\mathrm{DAS}_{\mathrm{D}} \\
{[\mu \mathrm{m}]}\end{array}$ & $\mathrm{g}_{\mathrm{D}},{ }^{\mathrm{E}}[\%]$ & $\begin{array}{c}g_{[4],}, \\
{[\%]}\end{array}$ & $\mathrm{g}_{\mathrm{CAFE}},{ }^{\mathrm{E}}[\%]$ \\
\hline \multirow{2}{*}{4} & \multirow{2}{*}{7.81} & Triggered & 4.37 & 20. & 7.91 & - & 7.36 \\
\hline & & spontaneous & 4.14 & 30. & 5.6 & 5.62 & $6.8^{(2)}$ \\
\hline \multirow{2}{*}{14} & \multirow{2}{*}{35.33} & Triggered & 13.81 & 15. & 31.45 & - & 34.6 \\
\hline & & spontaneous & 12.74 & 25. & 29. & 32.15 & $33.48^{(2)}$ \\
\hline \multirow{2}{*}{24} & \multirow{2}{*}{67.64} & Triggered & 21.99 & 10. & 61.62 & - & 65. \\
\hline & & spontaneous & 20.7 & 15. & 57.2 & 57.5 & $67 .^{(2)}$ \\
\hline
\end{tabular}

${ }^{(1)}$ Calculated with $\mathrm{w}_{0}$ and the data for the phase diagram given in Table $2 .{ }^{(2)} \mathrm{Using} \Delta \mathrm{T}_{\mathrm{N}}{ }^{\mathrm{E}}=0 \mathrm{~K}$.

Table 4. Summary of the measurements for the average over the sample sections of the $\mathrm{Cu}$ composition, $\mathrm{w}_{\mathrm{D}}$, the dendrite arm spacing, $\mathrm{DAS}_{\mathrm{D}}$, and the volume fraction of eutectic, $g_{D}$, ${ }^{E}$, compared with the predictions using the present CAFE model, $g_{C A F E},{ }^{E}$, a semi-analytical model, $\mathrm{g}_{[4]}, \mathrm{E}$ [4], as well as the Gulliver-Scheil prediction, $\mathrm{g}_{\mathrm{GS}},{ }^{\mathrm{E}}$. 